\title{
Control of GluR1 AMPA Receptor Function by cAMP-Dependent Protein Kinase
}

\author{
T. G. Banke, ${ }^{1,2}$ D. Bowie, ${ }^{1}$ H.-K. Lee, ${ }^{3}$ R. L. Huganir, ${ }^{3}$ A. Schousboe, ${ }^{2}$ and S. F. Traynelis ${ }^{1}$ \\ ${ }^{1}$ Department of Pharmacology, Emory University School of Medicine, Atlanta, Georgia 30322, 2Department of \\ Pharmacology, Royal Danish School of Pharmacy, Copenhagen, Denmark DK-2100, and ${ }^{3 H o w a r d ~ H u g h e s ~ M e d i c a l ~}$ \\ Institute, Johns Hopkins University School of Medicine, Baltimore, Maryland 21205
}

Modulation of postsynaptic AMPA receptors in the brain by phosphorylation may play a role in the expression of synaptic plasticity at central excitatory synapses. It is known from biochemical studies that GluR1 AMPA receptor subunits can be phosphorylated within their $\mathrm{C}$ terminal by $\mathrm{CAMP}$-dependent protein kinase $A(P K A)$, which is colocalized with the phosphatase calcineurin (i.e., phosphatase $2 \mathrm{~B}$ ). We have examined the effect of PKA and calcineurin on the time course, peak open probability $\left(P_{\mathrm{O}, \mathrm{PEAK}}\right)$, and single-channel properties of glutamateevoked responses for neuronal AMPA receptors and homomeric GluR1(flip) receptors recorded in outside-out patches. Inclusion of purified catalytic subunit $\mathrm{C} \alpha-\mathrm{PKA}$ in the pipette solution increased neuronal AMPA receptor $P_{\text {O,PEAK }}(0.92)$ compared with recordings made with calcineurin included in the pipette $\left(P_{\text {O,PEAK }}\right.$ 0.39). Similarly, C $\alpha$-PKA increased $P_{\text {O,PEAK }}$ for recombinant GluR1 receptors (0.78) compared with patches excised

Ionotropic glutamate receptors are ligand-gated ion channels that mediate excitatory neurotransmission in the mammalian CNS. These glutamate receptors can be subdivided on the basis of agonist pharmacology and sequence homology into three classes, which include $N$-methyl-D-aspartate, kainate, and AMPA receptors. AMPA receptors mediate fast synaptic current at most excitatory synapses and are tetrameric or pentameric complexes assembled from any of four different subunits (GluR1-4) with variable stoichiometry (Hollmann and Heinemann, 1994; Dingledine et al., 1999).

The modulation of excitatory synaptic transmission during long-term potentiation (LTP) and long-term depression (LTD), two well established cellular models of learning and memory, results from changes in the presynaptic release of glutamate and/or changes in postsynaptic glutamate receptor function or localization (Linden, 1994; Kullmann and Siegelbaum, 1995; Maren and Baudry, 1995; Rison and Stanton, 1995; Asztely and Gustafsson, 1996; Levenes et al., 1998; Carroll et al., 1999;

\footnotetext{
Received June 1, 1999; revised Oct. 6, 1999; accepted Oct. 13, 1999.

This work was generously supported by the Danish State Biotechnology Program (T.G.B.), the Howard Hughes Medical Institute (R.L.H.), the Danish Medical Research Council (A.S.), and the National Institute of Neurological Diseases and Stroke (S.F.T.). We thank Drs. M. Chalfie, S. Heinemann, T. J. Murphy, P. Seeburg, and M. Uhler for sharing cDNA constructs. We also thank Drs. J. Howe and M. L. Mayer for providing critical comments on this manuscript, J. Howe for sharing unpublished single channel data, M. Heckmann for sharing unpublished data concerning GluR6 kinetics, and P. Lyuboslavsky for excellent technical assistance.

Correspondence should be addressed to Dr. Stephen F. Traynelis, Department of Pharmacology, 5025 Rollins Research Center, Emory University, 1510 Clifton Road, Atlanta GA 30322-3090. E-mail: straynelis@pharm.emory.edu.

Copyright (C) 1999 Society for Neuroscience 0270-6474/99/200089-14\$15.00/0
}

from cells cotransfected with a cDNA encoding the PKA peptide inhibitor PKI $\left(P_{\text {O,PEAK }} 0.50\right)$ or patches with calcineurin included in the pipette ( $P_{\text {O,PEAK }}$ 0.42). Neither PKA nor calcineurin altered the amplitude of single-channel subconductance levels, weighted mean unitary current, mean channel open period, burst length, or macroscopic response waveform for recombinant GluR1 receptors. Substitution of an amino acid at the PKA phosphorylation site (S845A) on GluR1 eliminated the PKA-induced increase in $P_{\mathrm{O}, \mathrm{PEAK}}$, whereas the mutation of a $\mathrm{Ca}^{2+}$,calmodulin-dependent kinase II and PKC phosphorylation site (S831A) was without effect. These results suggest that AMPA receptor peak response open probability can be increased by PKA through phosphorylation of GluR1 Ser845.

Key words: AMPA receptors; glutamate; LTD; PKA; calcineurin; open probability; GluR1

Malenka and Nicoll, 1999). Although the molecular mechanisms underlying LTP and LTD are not yet fully understood, the complex regulation of protein phosphorylation by intracellular second messengers plays an essential role in the induction and maintenance of certain forms of LTP and LTD. For example, protein kinase A (PKA) is transiently activated during hippocampal LTP (Roberson and Sweatt, 1996) and has been suggested to be important for both postsynaptic as well as presynaptic mechanisms underlying LTD and LTP (Kameyama et al., 1998; Tzounopoulos et al., 1998; Yan-You and Kandel, 1998). Calcineurin, which is activated by $\mathrm{Ca}^{2+}$ and calmodulin, is colocalized with PKA at A kinase anchor proteins (AKAPs) in neurites (Coghlan et al., 1995; Fraser and Scott, 1999), suggesting that these two enzymes are well positioned to exert opposing actions on their substrates. Potentiation of postsynaptic responses by inhibition of postsynaptic calcineurin appears to occlude induction of LTP (Wang and Stelzer, 1994; Wang and Kelly, 1997); calcineurin has also been suggested to play a role in LTD (Mulkey et al., 1994).

Both neuronal and recombinant AMPA receptors can be phosphorylated by PKA at Ser845 (Fig. 1), a site consistent with known consensus sequences (RXS) (Pearson and Kemp, 1991; Blackstone et al., 1994; Roche et al., 1996; Mammen et al., 1997). Phosphorylation of recombinant AMPA receptors by PKA appears to potentiate their function (Keller et al., 1992; Roche et al., 1996), suggesting that the Ser845 phosphorylation could control some aspects of postsynaptic expression of LTP and LTD. Phosphorylation of the GluR1 subunit could change channel function by altering the unitary current amplitude, relative proportions of subconductance levels, number of active channels, receptor de- 
Figure 1. Structure of the GluR1 subunit. $A$, Linear schematic model showing the amino acid sequence (below) and numbering (above) for the C-terminal region of the GluR1 subunit. The four putative membrane-associated domains (M1-M4) (Hollmann and Heinemann, 1994) are indicated by boxes. The proposed transmembrane topology is indicated above (Dingledine et al., 1999). The regions suggested to show homology with the bacterial periplasmic amino acid-binding protein LAOBP (lysinearginine-ornithine binding protein), which are referred to as S1- and S2segments by Stern-Bach et al. (1994), are indicated above the GluR1 subunit. Several previous studies have shown Ser831 to be a substrate for phosphorylation by PKC and Ca ${ }^{2+}$, calmodulin-dependent kinase II (CAMKII), and Ser845 to be a substrate for phosphorylation by PKA (see Results). sensitization, or peak open probability. To understand the mechanism underlying the effects of PKA on AMPA receptors, we studied the time course and variance of macroscopic current responses evoked by maximal concentrations of glutamate rapidly applied to excised membrane patches containing neuronal or recombinant AMPA receptors. These experiments were supported by single-channel analysis of steady-state responses to low concentrations of glutamate and analysis of mutant GluR1 subunits lacking Ser845 and Ser831.

Some of these results have been published previously (Banke and Traynelis, 1998).

\section{MATERIALS AND METHODS}

Tissue culture and cDNA transfection. Human embryonic kidney (HEK) 293 cells (ATCC 1573) were plated on $12 \mathrm{~mm}$ glass coverslips coated with poly-D-lysine $(10-60 \mu \mathrm{g} / \mathrm{ml})$ or $35 \mathrm{~mm}$ plastic culture dishes and maintained in humidified $95 \% \mathrm{O}_{2} / 5 \% \mathrm{CO}_{2}$ in DMEM (Gibco 11960) as previously described (Traynelis and Wahl, 1997; Bowie et al., 1998). HEK 293 cells were transiently transfected (Chen and Okayama, 1987) with $0.1-1.0 \mu \mathrm{g} / \mathrm{ml}$ GluR1(flip) (provided by S. F. Heinemann, Salk Institute) in a CMV-based mammalian expression vector. A reporter cDNA encoding Green Fluorescent Protein [(GFP) 0.2-0.4 $\mu \mathrm{g} / \mathrm{ml}$; Columbia University; Marshall et al. (1995)] was used to identify individually transfected cells. In some cells, $0.2-0.4 \mu \mathrm{g} / \mathrm{ml}$ of cDNA encoding the catalytic subunit $\mathrm{C} \alpha$-PKA (Huggenvik et al., 1991) (provided by M. Uhler, University of Michigan) or a cDNA encoding a fusion protein of GFP and the PKA inhibitor peptide PKI (Wang and Murphy, 1998) (provided by T. J. Murphy, Emory University) were cotransfected with GluR1 into cells $(0.1-1.0 \mu \mathrm{g} / \mathrm{ml})$.

Immunoblot analysis. HEK-293 cells grown on $10 \mathrm{~cm}$ dishes were transiently transfected with either the wild-type GluR1 $(5 \mu \mathrm{g} / \mathrm{dish})$ or S845A mutant GluR1 (5 $\mu \mathrm{g} /$ dish) as described above (also see Roche et al., 1996). In some cases, the HEK293 cells were cotransfected with a cDNA encoding C $\alpha$-PKA (1-2 $\mu \mathrm{g} / \mathrm{dish})$ or PKI-GFP (3-5 $\mu \mathrm{g} / \mathrm{dish})$. The cells were then harvested $48 \mathrm{hr}$ after the transfection and were lysed and sonicated in ice-cold buffer containing (in mM): $150 \mathrm{NaCl}, 50 \mathrm{NaF}, 10$ $\mathrm{NaH}_{2} \mathrm{PO}_{4}, 5$ EDTA, 5 EGTA, 10 sodium pyrophosphate, 1 sodium vanadate, plus $10 \mathrm{U} / \mathrm{ml}$ aprotinin and $1 \mu \mathrm{M}$ okadaic acid, $\mathrm{pH}$ 7.0. A membrane fraction was generated from the lysate by centrifugation at $14,000 \times g$ for $10 \mathrm{~min}$ at $4^{\circ} \mathrm{C}$. The resulting membrane pellet was resuspended in sample buffer composed of $10 \%$ glycerol (v/v), $5 \%$ $\beta$-mercaptoethanol (v/v), $2 \%$ SDS (v/v), and a trace amount of pyronin $\mathrm{Y}$, in Tris- $\mathrm{HCl}$ buffer, $\mathrm{pH} 6.8$, and boiled for $5 \mathrm{~min}$. The samples were run on a $7.5 \%$ polyacrylamide gel, which was then transferred to polyvinylidene fluoride (PVDF) membranes for immunoblot analysis.

PVDF membranes were incubated in blocking buffer consisting of $1 \%$ bovine serum albumin and $0.1 \%$ Tween-20 in PBS for $1 \mathrm{hr}$. The PVDF membranes were then incubated for $2 \mathrm{hr}$ at room temperature in phosphorylation site-specific antibodies that recognize phosphorylated Ser831 (1:1000 dilution) or Ser845 (1:250 dilution) on GluR1. The phosphorylation site-specific antibodies have been characterized previously (Mammen et al., 1997). The PVDF membranes were washed five times for 5 min in blocking buffer and incubated for $1 \mathrm{hr}$ in alkaline phosphatase- linked secondary antibody (1:10,000 dilution; Pierce, Rockford, IL). After final washes in blocking buffer (five times for $5 \mathrm{~min}$ ), enhanced chemifluorescence (ECF) substrate (Amersham, Arlington Heights, IL) was applied on the membranes for $\geq 5 \mathrm{~min}$. The membranes were dried between filter papers and scanned directly on a Storm 860 scanner (Molecular Dynamics, Sunnyvale, CA) to measure fluorescence using blue chemiluminescence mode at $650-900 \mathrm{~V}$. The fluorescence signals were quantified using ImageQuant software (Molecular Dynamics). The immunoblots using phosphorylation site-specific antibodies were subsequently stripped and reprobed with an antibody that recognizes the GluR1 C terminus (1:5000 dilution). The degree of GluR1 phosphorylation at Ser845 and Ser831 was analyzed by normalizing the signal from phosphorylation site-specific antibody to the total amount of GluR1 measured using an antibody against the GluR1 C terminus.

Acute dissociation of hippocampal pyramidal cells. Hippocampal CA1 pyramidal neurons were dissociated as previously described by Washburn et al. (1997) from $300 \mu \mathrm{m}$ hippocampal slices from 12- to 17-d-old rats that were decapitated under deep isofluorane anesthesia; slices were allowed to recover in artificial CSF bubbled with $95 \% \mathrm{O}_{2} / 5 \% \mathrm{CO}_{2}$ with a composition of (in mM): $124 \mathrm{NaCl}, 2.5 \mathrm{KCl}, 1 \mathrm{NaH}_{2} \mathrm{PO}_{4}, 26 \mathrm{NaHCO}_{3}$, $1 \mathrm{CaCl}_{2}, 1.4 \mathrm{MgCl}_{2}, 10$ glucose. One to four hours after preparation, slices were incubated in DMEM supplemented with pronase E (0.5-1.0 $\mathrm{mg} / \mathrm{ml}$; Sigma, St Louis, MO), $4 \mathrm{~mm} \mathrm{MgCl}_{2}$, and $1 \mathrm{~mm}$ kynurenate and bubbled with $95 \% \mathrm{O}_{2} / 5 \% \mathrm{CO}_{2}$ for $15-45 \mathrm{~min}$. Slices were washed with HEPES buffered saline supplemented with $5 \mathrm{mM} \mathrm{MgCl}_{2}$ and $10 \mathrm{~mm}$ glucose, and the CA1 region including stratum pyramidale was microdissected. The tissue was triturated through a series of three increasingly narrow, fire-polished pipettes and plated on glass coverslips onto which $10 \mu \mathrm{l}$ of a 5:3 ratio of Cell-Tak and $0.1 \mathrm{M} \mathrm{NaHCO}_{3}$ had been dried. Cells were allowed to settle for $30 \mathrm{~min}$ before recording. Although our preparation will include both pyramidal cells and interneurons, we refer to the neurons studied here as pyramidal cells on the basis of their morphology and because they are the most numerous neuron in region CA1.

Xenopus oocyte injection and recording. Female Xenopus laevis were anesthetized using $0.1-0.2 \%$ ethyl 3 -aminobenzoate, and the ovaries were surgically removed. Stage V and VI oocytes were isolated after a 2 $\mathrm{hr}$ incubation of the ovaries in $2 \mathrm{mg} / \mathrm{ml}$ collagenase at room temperature. Oocytes were injected the following day with $60 \mathrm{ng}$ of cRNA encoding the GluR1(flip) receptor that was transcribed in vitro. Injected oocytes were maintained at $17^{\circ} \mathrm{C}$ in Barth's solution containing gentamycin sulfate $(0.1 \mathrm{mg} / \mathrm{ml})$ for $3-6 \mathrm{~d}$, after which recordings were made at $23^{\circ} \mathrm{C}$ from cells continuously perfused in a solution containing (in $\mathrm{mM}$ ): 115 $\mathrm{NaCl}, 5 \mathrm{HEPES}, 2 \mathrm{KCl}, 1.8 \mathrm{CaCl}_{2}$, pH 7.0. Recording pipettes were filled with $3 \mathrm{M} \mathrm{KCl}$. Glutamate $(100 \mu \mathrm{M})$ was used to activate steady-state current responses recorded from oocytes under two-electrode voltage clamp. After three control responses to glutamate were measured, 5-20 $\mathrm{nl}$ of purified $\mathrm{C} \alpha$-PKA $(0.6 \mathrm{U} / \mathrm{nl})$ or enzyme buffer was injected into each oocyte with an Eppendorf Microinjector 5242. Approximately $20 \mathrm{~min}$ later a test glutamate response was evoked, and potentiation was calculated as the ratio of the amplitude of the test response to the control response.

Recordings of macroscopic current responses in excised membrane patches. A piezobimorph-driven double-barreled perfusion system was used to rapidly apply the endogenous neurotransmitter glutamate (10 $\mathrm{mm}$ ) onto excised membrane patches for $100-200 \mathrm{msec}$, as previously 


\begin{tabular}{lcccrc}
\hline \multicolumn{7}{l}{ Table 1. Composition of internal recording solutions } \\
& \multicolumn{7}{c}{ PKA } & PKA & \\
& Units & ATP & AMP-PNP & PKI & Calcineurin \\
\hline Gluconic acid & $\mathrm{mM}$ & 110 & 110 & 110 & 110 \\
$\mathrm{CsCl}$ & $\mathrm{mM}$ & 30 & 30 & 30 & 30 \\
$\mathrm{NaCl}$ & $\mathrm{mM}$ & 4 & 4 & 4 & 4 \\
$\mathrm{HEPES}$ & $\mathrm{mM}$ & 5 & 5 & 5 & 5 \\
$\mathrm{BAPTA}$ & $\mathrm{mM}$ & 5 & 5 & 5 & \\
EGTA & $\mathrm{mM}$ & & & & 4.16 \\
$\mathrm{CaCl}{ }_{2}$ & $\mathrm{mM}$ & 0.5 & 0.5 & 0.5 & 2.1 \\
Free Ca & $\mathrm{nM}$ & $<10$ & $<10$ & $<10$ & 100 \\
$\mathrm{MgCl}_{2}$ & $\mathrm{mM}$ & 2 & 2 & 2 & 2.27 \\
$\mathrm{ATP} / \mathrm{AMP}-\mathrm{PNP}$ & $\mathrm{mM}$ & 4 & 4 & & \\
$\mathrm{GTP}$ & $\mathrm{mM}$ & 0.3 & & & \\
PKI & $\mu \mathrm{M}$ & & & 4.5 & 4.5 \\
$\mathrm{Calmodulin}$ & $\mu \mathrm{g} / \mathrm{ml}$ & & & & 10 \\
$\mathrm{C} \alpha$-PKA & $\mathrm{U} / \mathrm{ml}$ & $125-300$ & $125-300$ & & \\
$\mathrm{Calcineurin}$ & $\mathrm{U} / \mathrm{ml}$ & & & & 0.2 \\
\hline
\end{tabular}

described (Traynelis and Wahl, 1997). The agonist application barrel was preflushed for $1-4 \mathrm{sec}$ to remove any dilute solution at the tip. The time course of solution exchange across the laminar flow interface was estimated by liquid junction potential measurements to be $0.2-0.4 \mathrm{msec}$ (10-90\% rise time) for a 10-fold difference in ionic strength; the time course of the junction potential change for our perfusion system was measured at the end of most experiments. External recording solution for all experiments was (in mM): $150 \mathrm{NaCl}, 10 \mathrm{HEPES}, 3 \mathrm{KCl}, 1 \mathrm{CaCl}_{2}$, $1 \mathrm{MgCl}_{2}, 10-20$ mannitol, $\mathrm{pH} 7.4 ; 310-330$ mOsm. All experiments were performed at $23^{\circ} \mathrm{C}$. Borosilicate glass pipettes $[1.65 \mathrm{~mm}$ outer diameter (OD), $1.15 \mathrm{~mm}$ inner diameter (ID)] had resistances after fire-polishing of 7-9 $\mathrm{M} \Omega$. The internal solutions used are described in Table 1; $\mathrm{pH}$ was adjusted to 7.3 using $\mathrm{CsOH}$, and osmolality was 290-300 mOsm. Spermine $(0.1 \mathrm{mM})$ was included in the internal solution for all experiments measuring macroscopic current-variance relationship except some experiments in which cells were cotransfected with a cDNA encoding $\mathrm{C} \alpha$-PKA or PKI. In one set of experiments, $\mathrm{Na}_{2} \mathrm{ATP}$ was replaced by the nonhydrolyzable analog 5'-adenylylimido-diphosphate ( $\mathrm{Na}_{2} \mathrm{AMP}-\mathrm{PNP}$; Sigma). C $\alpha$-PKA, PKI, and calcineurin were obtained from Promega (Madison, WI), and calmodulin was obtained from Upstate Biotechnology (Lake Placid, NY). Biochemical assays of phosphate liberation from $p$-nitrophenyl phosphate added to our internal recording solution verified that the phosphatase activity we observed with the addition of calcineurin was dependent on divalent ions and calmodulin. Internal solutions that contained calmodulin and/or calcineurin were stored during the experiment in a glass syringe on ice.

Nonstationary variance analysis of macroscopic current responses. Native and recombinant AMPA receptors open to several conductance levels (Dingledine et al., 1999). Barring the isolation of patches that contain a single active channel, it is difficult to ascertain the properties of nondesensitized single channels activated by maximal concentrations of glutamate because multiple openings and multiple conductance levels confound single-channel analysis. In such situations, variance analysis of macroscopic currents can be used to obtain an estimate both of the probability that a channel is open at the peak of the response and the weighted mean unitary current (Cull-Candy et al., 1988). Sigworth (1980) was the first to extend variance analysis to nonstationary currents (for review, see Heinemann and Conti, 1992), and several studies of this method suggest that it can provide reliable results when carefully applied to high quality data (Silberberg and Magleby, 1993; Traynelis and Wahl, 1997; Traynelis and Jaramillo, 1998).

We have used nonstationary variance analysis of current responses to estimate conductance and $P_{\mathrm{O}, \mathrm{PEAK}}$ for GluR1 receptors activated by 10 mM glutamate. Between 20 and 150 glutamate-evoked current responses (mean 59) were typically recorded at a sampling frequency of $50 \mathrm{kHz}$ (2-5 kHz eight-pole Bessel filter; cutoff frequencies are $-3 \mathrm{~dB}$ ). Responses in excised patches showed on average $19 \%$ rundown during the experiment ( $0.43 \%$ rundown per event; 130 patches). Experiments with $>1 \%$ rundown per response were excluded, although they gave qualita- tively similar results to experiments without any detectable rundown. For all patches, local averages of five current responses were made to estimate the response waveform, and variance was analyzed as previously described (Traynelis and Wahl, 1997). The current-variance relationship was analyzed in two ways. First, the current-variance plot for each patch was fitted by the equation:

$$
\operatorname{Variance}_{(t)}=i I(t)-I(t)^{2} / N+\text { Variance }_{\mathrm{BASE}},
$$

where $i$ is the mean weighted unitary current, $I(t)$ is the macroscopic current, $N$ is the number of channels, and Variance $_{\text {BASE }}$ is the baseline variance (Neher and Stevens, 1977). A simplex algorithm (least squares criterion) or a Levenberg-Marquardt algorithm was used to obtain the best fit $\left(\mathrm{X}^{2}\right.$ criterion) of this equation to the data. Variance $_{\mathrm{BASE}}$ was forced to be $>0.0$ during the fitting procedure. $P_{\mathrm{O}, \mathrm{PEAK}}$ was calculated by:

$$
P_{\mathrm{O}, \mathrm{PEAK}}=I_{\mathrm{PEAK}} /(i N) \text {, }
$$

where $I_{\text {PEAK }}$ is the maximum current response. Different portions of the current-variance curve containing 60,80 , and $100 \%$ of the data set (always including low current values) were fitted by Equation 1 and gave similar estimates for unitary current ( $p>0.5$; ANOVA; power to detect $0.3 \mathrm{pA}$ difference was $0.6-0.7$ for measurements in Table 2), as expected if our variance measurements were free of amplitude-dependent artifacts and desensitization-linked changes in conductance. The mean value for $P_{\mathrm{O}, \mathrm{PEAK}}$ from fits obtained to 80 and $100 \%$ of the current-variance plot is reported for experiments in Results. The stochastic nature of responses and inherent variability of this approach accounts for about half of the variability in our $P_{\mathrm{O} \text {,PEAK }}$ measurements (data not shown).

The second method we used to analyze response variance was to calculate Variance $_{\text {NORM }}(t)$ by dividing the variance of each bin of a given response by the response amplitude. This reduces the abscissa to unity, converts the units on the ordinate to $\mathrm{pA}$, and allows data from patches with different response amplitudes to be pooled because unitary conductance and $P_{\mathrm{O}, \text { PEAK }}$ were independent of response amplitude $(|\mathrm{R}|=$ $0.09-0.35$; mean $0.13 ; p>0.05$ for all conditions). The normalized current-variance plots were fitted by the equation:

$$
\text { Variance }_{\mathrm{NORM}}(t)=i I_{\mathrm{NORM}}(t)-I_{\mathrm{NORM}}(t)^{2} / N_{\mathrm{NORM}}+\text { base }_{\mathrm{NORM}}
$$

where $I(t)_{\text {NORM }}$ and base $_{\text {NORM }}$ are the normalized current and normalized baseline variance:

$$
N_{\text {NORM }}=N / I_{\text {PEAK }},
$$

and

$$
P_{\mathrm{O}, \mathrm{PEAK}}=1 /\left(i N_{\mathrm{NORM}}\right) \text {. }
$$

These two methods produced similar values for $i$ and $P_{\mathrm{O} \text {,PEAK }}$ for responses to maximal glutamate. Chord conductance levels were calculated for a reversal potential of $0 \mathrm{mV}$.

The existence of subconductance levels can increase the current variance at high values of $P_{\mathrm{O}, \mathrm{PEAK}}$ and complicate the analysis described above (Traynelis and Wahl, 1997). Colquhoun and Hawkes (1977) have provided a general solution to the problem of calculating the variance for a receptor with multiple conductance levels that can be written in nonmatrix time-dependent form (Sigworth, 1980) as:

$$
\operatorname{Variance}(t)=N\left\{\sum_{J=1}^{k} p(t) p_{\mathrm{O}, \mathrm{PEAK}, J} i_{J}^{2}-\left(\sum_{J=1}^{k} p(t) p_{\mathrm{O}, \mathrm{PEAK}, J} i_{\mathrm{J}}\right)^{2}\right\},
$$

where $k$ is the number of sublevels, $p(t)$ is the time-dependent response waveform, which is 1 at the peak response, and $p_{\mathrm{O}, \mathrm{PEAK}, \mathrm{J}}$ is the probability that the subconductance level $J$ with unitary current $i_{\mathrm{J}}$ is open at the peak of the response. $P_{\mathrm{O}, \mathrm{PEAK}}$ is the sum of $p_{\mathrm{O}, \mathrm{PEAK}, \mathrm{J}}$ for $k$ sublevels. The relative contributions of the sublevels are assumed to be constant throughout the decay of response waveform, although this may not be true for the brief rising phase of the response (Rosenmund et al., 1998), which was omitted from analysis (see Discussion). We have used this expression to determine whether shifts in the relative proportions of subconductance levels might have accounted for an apparent difference in $P_{\mathrm{O} \text { PEAK }}$ that we calculate from Equations 1-5 for current-variance curves constructed from recordings made with calcineurin and purified $\mathrm{C} \alpha$-PKA included in the pipette. To do this we generated a $p(t)$-variance relationship from Equation 6 for a receptor with a single conductance level $(k=1)$ using $P_{\mathrm{O}, \mathrm{PEAK}}$ and the weighted mean chord conductance 
Table 2. Control of GluR1 function by PKA and calcineurin

\begin{tabular}{|c|c|c|c|c|c|c|c|c|}
\hline & $\begin{array}{l}\gamma_{\mathrm{CHORD}} \\
(\mathrm{pS})\end{array}$ & $\begin{array}{l}10-90 \% \text { rise } \\
\text { time (msec) }\end{array}$ & $\begin{array}{l}\operatorname{tau}_{\mathrm{DECAY} 1} \\
(\mathrm{msec})\end{array}$ & $\begin{array}{l}\operatorname{tau}_{\text {DECAY2 }} \\
(\mathrm{msec})\end{array}$ & $\begin{array}{l}\text { Open period } \\
(\mathrm{msec})\end{array}$ & $\begin{array}{l}\text { Burst } \\
\text { length } \\
\text { (msec) }\end{array}$ & $\begin{array}{l}\mathrm{SS} / \text { peak } \\
\text { ratio }\end{array}$ & $N$ \\
\hline Native AMPA-R + PKA & $12 \pm 1$ & $0.44 \pm 0.02$ & $5.23 \pm 0.25$ & $30.0 \pm 1.8$ & & & $0.02 \pm 0.01$ & 6 \\
\hline Native AMPA-R + calcineurin & $11 \pm 0.3$ & $0.41 \pm 0.01^{*}$ & $5.36 \pm 0.39$ & $33.0 \pm 2.9$ & & & $0.05 \pm 0.01$ & 9 \\
\hline GluR1 + PKA & $14 \pm 1$ & $0.49 \pm 0.06$ & $2.72 \pm 0.15$ & & $0.56 \pm 0.08$ & 0.72 & $0.02 \pm 0.01$ & 13,7 \\
\hline GluR1 + calcineurin & $13 \pm 1$ & $0.56 \pm 0.02$ & $2.63 \pm 0.11$ & & $0.60 \pm 0.06$ & 0.80 & $0.02 \pm 0.01$ & 10,6 \\
\hline GluR1 + PKI & $14 \pm 1$ & $0.53 \pm 0.02$ & $2.75 \pm 0.17$ & & & & $0.02 \pm 0.01$ & 11 \\
\hline
\end{tabular}

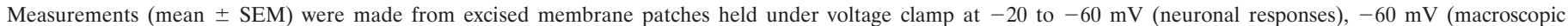

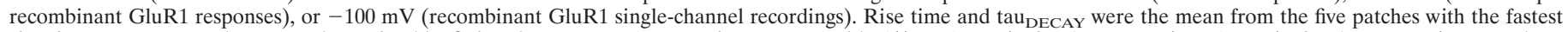

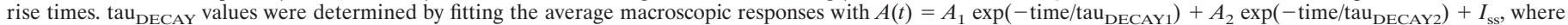

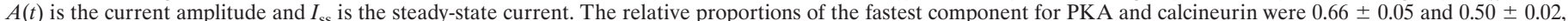

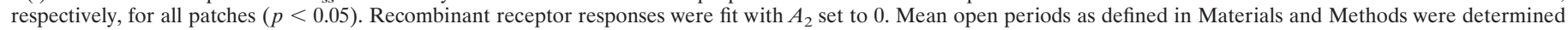

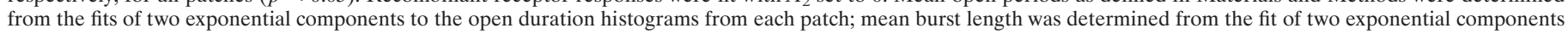

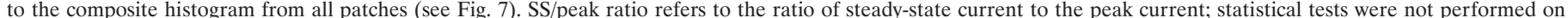

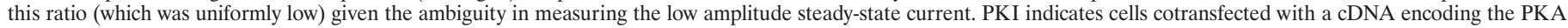

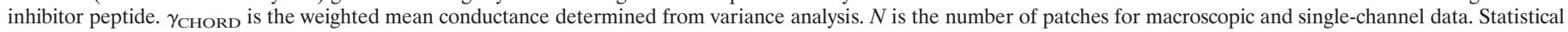

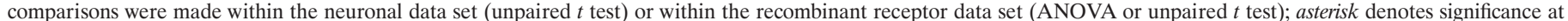
$p<0.05$. Power to detect a $4.7 \mathrm{pS}, 0.18 \mathrm{msec}, 2 \mathrm{msec}$, or $0.2 \mathrm{msec}$ difference in $\gamma$, rise time, tau ${ }_{\mathrm{DECAY}}$, or mean open time at $\alpha=0.05$ ranged between 0.6 and 0.9 .

determined from variance analysis. We then compared this representation of our data with $2 \times 10^{9}$ theoretical curves generated from Equation 6 using conductance levels determined from our single-channel analysis (see Table 4 ) and $p_{\mathrm{O}, \mathrm{PEAK}, \mathrm{J}}$ values for each sublevel ranging from 0 to 1 in steps of 0.0005. The sum of squares differences between the theoretical relationships and our data were evaluated to obtain the set of solutions for Equation 6 given our measured subconductance level amplitudes.

Recording and analysis of unitary GluR1 currents in excised membrane patches. Recordings of single-channel currents in excised membrane patches from HEK 293 cells expressing wild-type GluR1 were made as described above, except that we used Sylgard-coated thick-walled borosilicate micropipettes $(1.5 \mathrm{~mm}$ OD, $0.86 \mathrm{~mm}$ ID) with resistances of 15-25 M $\Omega$. Single-channel activity was evoked using a submaximal concentration of glutamate $(10 \mu \mathrm{M})$, and records were digitized at $20 \mathrm{kHz}$ and filtered off-line using a Gaussian filter $(-3 \mathrm{~dB}$, cutoff $1 \mathrm{kHz})$. Single-channel currents activated by glutamate are brief and of low amplitude and thus difficult to distinguish from momentary seal breakdown or other noise. To obtain a reliable estimate of the relative amplitudes of subconductance states, we took two measures to ensure that the signals we analyzed arose from glutamate-activated channels. First, in 11 patches in which current recordings were analyzed for single-channel openings in the absence of glutamate and the presence of 10-50 $\mu \mathrm{M}$ CNQX, the frequency of apparent transitions was on average 9.4-fold lower than in the presence of $10 \mu \mathrm{M}$ glutamate $(p<0.001$; mean control current amplitude $-0.4 \mathrm{pA}$ ), suggesting that the events we measure arise from glutamate gating of homomeric GluR1. Second, only patches with an rms value $<0.11 \mathrm{pA}(1 \mathrm{kHz}$ filter) for control records were included in analysis (mean rms $0.09+0.004 \mathrm{pA} ; n=13$ patches). Single-channel openings were analyzed using the time course fitting method (software provided by D. Colquhoun, University College London); transitions briefer than $2.0 \times$ filter-rise times (i.e., $98 \%$ of full amplitude) were excluded from the analysis of amplitude histograms. All apparent transitions greater in amplitude than $2 \times$ rms between the open and closed states were fitted, and the resulting idealized records were revised by imposition of a minimum resolvable duration for openings and shuttings $(120 \mu \mathrm{sec})$ (Colquhoun and Sigworth, 1995); refitting of the data imposing a $200 \mu \mathrm{sec}$ resolution produced similar results. The false event rate for detection of $8 \mathrm{pS}$ sublevels is $0.0001 \mathrm{sec}^{-1}$; however, this rises to $0.5 \mathrm{sec}^{-1}$ for conductance levels that match our lowest detected openings in our best patches (Colquhoun and Sigworth, 1995). The unbinned data comprising the amplitude histograms were fitted to the sum of two to four Gaussian components (maximum likelihood method; software provided by D. Colquhoun). The composite closed time distribution obtained for GluR1 single-channel currents from all patches recorded with PKA in the pipette was fitted with four exponential components, and a critical time ( $\left.T_{\mathrm{CRIT}}\right)$ was calculated to define bursts of openings from the two briefest shut time components $(0.5$ and $4 \mathrm{msec})$ such that the percentage of misclassified gaps is minimized (Colquhoun and Sigworth, 1995). Bursts defined by $T_{\text {CRIT }}$ of $1.0 \mathrm{msec}$ were fitted with the sum of two exponential components. If all agonist-bound channels open with a burst structure similar to that observed with $10 \mu \mathrm{M}$ glutamate, then the maximum achievable $P_{\mathrm{O}, \mathrm{PEAK}}$ can be estimated using:

$P_{\mathrm{O}, \mathrm{PEAK}, \mathrm{MAX}}=\langle\text { open period }\rangle^{*}\langle$ open periods per burst $\rangle /\langle$ burst length $\rangle$,

where $<$ burst length $>$ is the mean burst length calculated from the fitted components of the burst length distribution, <open periods per burst $>$ is defined as one plus the mean number of gaps within a burst, and <open period $>$ was the mean duration of open periods regardless of the sublevel amplitude calculated from the fitted open period histogram constructed from openings to all subconductance levels. More complex aspects of burst structure were not analyzed. Direct transitions between subconductance levels were considered to be a single open period.

Statistical analysis. Differences between measured parameters were assessed using ANOVA with Tukey post hoc testing. Where appropriate, Student's $t$ test was used. We rejected the null hypothesis at $p$ values $<0.05$ and calculated the power of ANOVA and $t$ tests that showed no significant difference (Zar, 1999).

\section{RESULTS}

\section{Control of neuronal AMPA receptor function by PKA}

PKA has previously been reported to enhance the function of recombinant and neuronal glutamate receptors (Dingledine et al., 1999). To determine whether PKA alters the function of hippocampal AMPA receptor response properties, we analyzed macroscopic glutamate receptor responses from patches excised from acutely dissociated CA1 pyramidal neurons with either $\mathrm{C} \alpha$-PKA or calcineurin added to the pipette solution (Fig. $2 A$ ). These neurons are known to express primarily GluR1 and GluR2 AMPA receptor subunits, as well as some GluR3 subunits (Boulter et al., 1990; Sommer et al., 1990; Monyer et al., 1991; Leranth et al., 1996). Rapid application of $10 \mathrm{~mm}$ glutamate to patches excised from the soma in the presence of $20 \mu \mathrm{M}$ MK-801 plus $1 \mathrm{~mm} \mathrm{Mg}^{2+}$ and in the nominal absence of glycine activated rapidly rising (mean $10-90 \%$ rise time $420 \mu \mathrm{sec} ; n=15$ ) and rapidly desensitizing current responses that reversed near $0 \mathrm{mV}$ (corrected for $+9 \mathrm{mV}$ junction potential; Fig. 2B). Glutamateevoked current responses could be best fit by two exponential components (mean from all cells tau ${ }_{\text {DECAY1 }}=5.8 \mathrm{msec}, 57 \%$; $\left.\operatorname{tau}_{\mathrm{DECAY} 2}=31 \mathrm{msec}, 43 \% ; n=15\right)$. The decay time course of these responses was similar to that described for dendritic AMPA receptors in CA1 pyramidal cells (Spruston et al., 1995) and was 
A
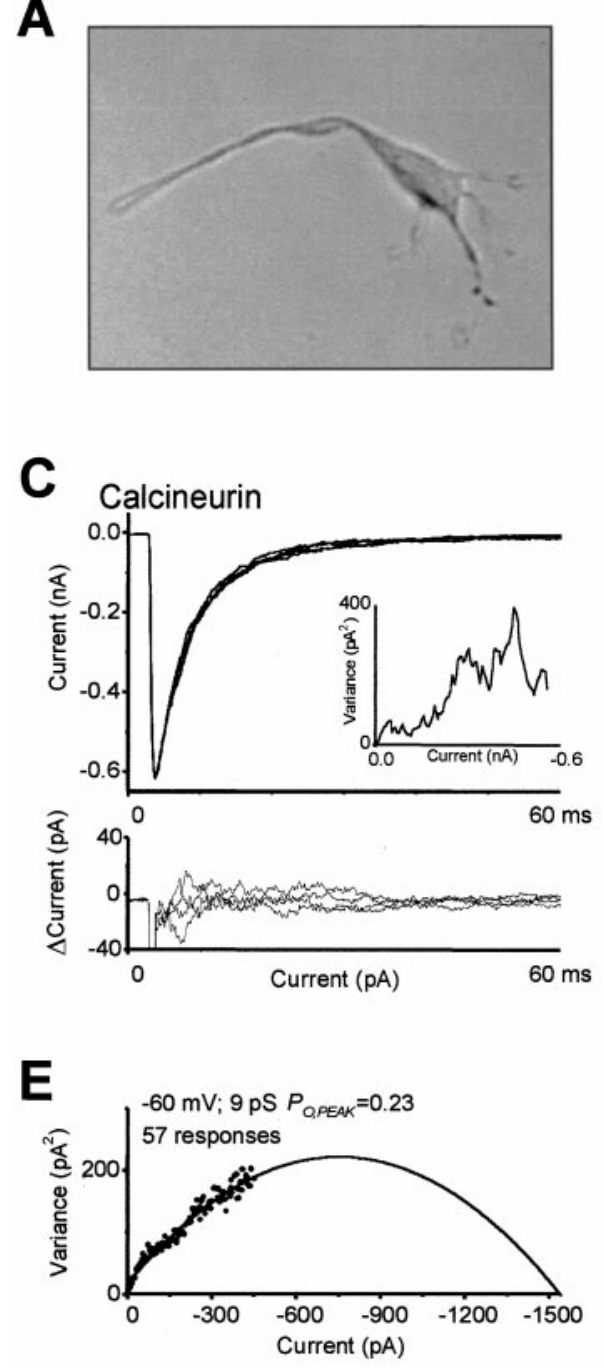

B

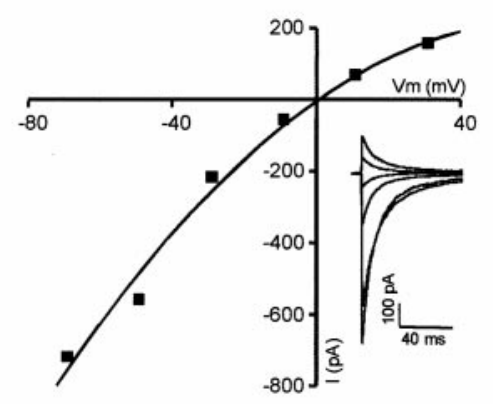

D

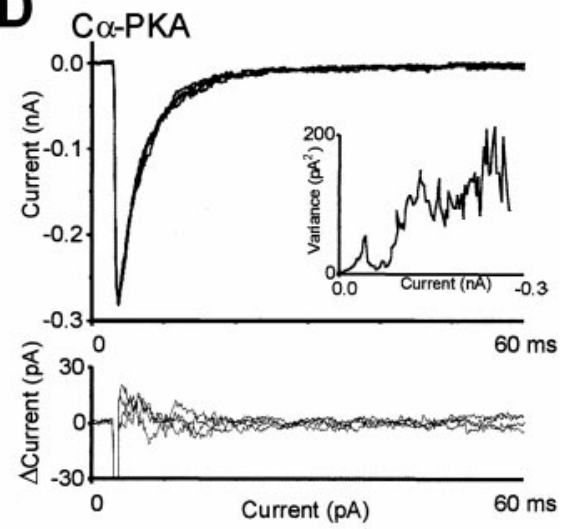

$\mathbf{F}$

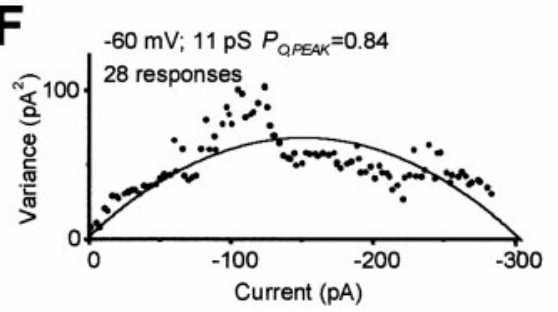

Figure 2. The catalytic subunit $\mathrm{C} \alpha$-PKA increases and calcineurin decreases neuronal AMPA receptor $P_{\mathrm{O} \text {, PEAK }} \cdot A$, Photomicrograph of an acutely dissociated CA1 hippocampal neuron. $B$, Typical current-voltage relationship for AMPA receptor responses in acutely dissociated hippocampal neurons, corrected for a $+9 \mathrm{mV}$ junction potential. Inset shows responses recorded at different potentials. $C, D$, Superimposed macroscopic current responses to $10 \mathrm{~mm}$ glutamate (plus $20 \mu \mathrm{M}$ MK-801) were recorded from an outside-out patch excised from acutely dissociated CA1 neurons held at $-60 \mathrm{mV}$. The difference currents between the mean waveform and each individual current are shown below. The insets show the current-variance plot for these responses. Responses were recorded with either calcineurin plus calmodulin $(C)$ or $\mathrm{C} \alpha$ PKA plus ATP $(D)$ included in the internal pipette solution; free $\mathrm{Ca}^{2+}$ was buffered to 100 nM for both patches. $E$, The composite currentvariance relationship from the patch in $C$ is shown for 57 macroscopic responses. $F$, The composite current-variance relationship from the patch in $D$ is shown for 28 macroscopic responses recorded with $\mathrm{C} \alpha$-PKA included in the pipette. The smooth curves in $E, F$ are Equation 1 fitted to the data; the chord conductance is shown assuming a reversal potential of $0 \mathrm{mV}$. not altered by inclusion of $\mathrm{C} \alpha$-PKA versus calcineurin in the pipette (Table 2). To evaluate whether PKA alters either the weighted mean unitary conductance or $P_{\mathrm{O} \text {,PEAK}}$, we performed nonstationary variance analysis of glutamate-evoked current responses. Figure $2 C, D$ shows fluctuations of the residual difference currents obtained by subtraction of the mean current waveform. These fluctuations arise from random properties of channel gating during glutamate application. Analysis of the currentvariance relationship of the difference currents shown in Figure $2 C, D$ (inset) highlights the stochastic nature of these fluctuations. The composite current-variance curves (Fig. 2E,F) constructed from many difference currents shows the parabolic form described by Equation 1. From these data we have estimated the weighted mean unitary current and the number of active channels and used these values to determine $P_{\mathrm{O}, \mathrm{PEAK}}$. When $\mathrm{C} \alpha$-PKA was included in the patch pipette, $P_{\text {O,PEAK }}$ was $0.92 \pm 0.01$ (mean $\pm \mathrm{SEM} ; n=$ 6; Fig. $2 D, F$ ), which was 2.4 -fold higher than $P_{\text {O,PEAK }}$ calculated from responses recorded when calcineurin plus calmodulin were included in the pipette $(0.39 \pm 0.02 ; n=9 ; p<0.001$; unpaired $t$ test) (Fig. 2C,E). The weighted mean conductance values were not significantly different with PKA or calcineurin included in the pipette (Table 2) and were similar to values obtained for glutamate activation of homomeric GluR1 receptors [Table 2; see also Derkach et al. (1999)] and for dendritic hippocampal AMPA receptors (Spruston et al., 1995). These results suggest that PKA can enhance hippocampal AMPA receptor function by increasing $P_{\mathrm{O}, \mathrm{PEAK}}$.

\section{Control of recombinant AMPA receptor function by PKA}

To evaluate the molecular basis for the PKA-induced increase in $P_{\text {O,PEAK }}$ that we observed in CA1 neurons, we recorded glutamate-induced current responses from recombinant AMPA receptors expressed in HEK 293 cells and Xenopus oocytes. We studied homomeric GluR1(flip) receptors because the C terminal of the GluR1 subunit has been shown to be a substrate for phosphorylation by PKA. Phosphorylation-induced increases in GluR1 receptor response amplitude previously have been observed after the addition of purified $\mathrm{C} \alpha$-PKA to the intracellular solution in whole-cell patch recordings (Roche et al., 1996). In confirmation of this result, we found that the glutamate-activated GluR1 current responses recorded under voltage clamp in Xenopus oocytes were significantly potentiated after microinjection of C $\alpha$-PKA (1.70 \pm 0.17 -fold; $n=13)$ compared with bufferinjected oocytes $(1.02 \pm 0.03$-fold; $p<0.05)$ (see also Keller et al., 1992). To test whether $\mathrm{C} \alpha$-PKA potentiates recombinant GluR1 function in a manner similar to neuronal AMPA receptor function, we studied the kinetic properties of macroscopic current 
Figure 3. Nonstationary variance analysis of GluR1 current responses obtained from an outside-out patch. $A$, Two GluR1 macroscopic current responses recorded from an excised membrane patch that was held at $-60 \mathrm{mV}$ and challenged with 10 mM glutamate for $160 \mathrm{msec}$ are superimposed. The difference currents between the mean waveform and each individual current are shown below. The inset shows the current-variance plot for these two responses. These responses were recorded from wild-type GluR1 with C $\alpha$-PKA included in the pipette. $B$, The composite current-variance relationship is shown for 90 macroscopic responses; the smooth curve is Equation 1 fitted to the data. $\gamma$ is the weighted mean chord conductance, and $N$ is the number of channels. $C$, Analysis of 60 consecutive agonist-induced responses in the excised membrane patch from $A$ and $B$ showed minimal run-down during the course of this experiment. Response characteristics such as peak amplitude (115 $\mathrm{pA}), 10-90 \%$ rise time $(0.5$ $\mathrm{msec}$ ), and exponential decay time constant $(3.1 \mathrm{msec})$ were stable during the experiment.
A
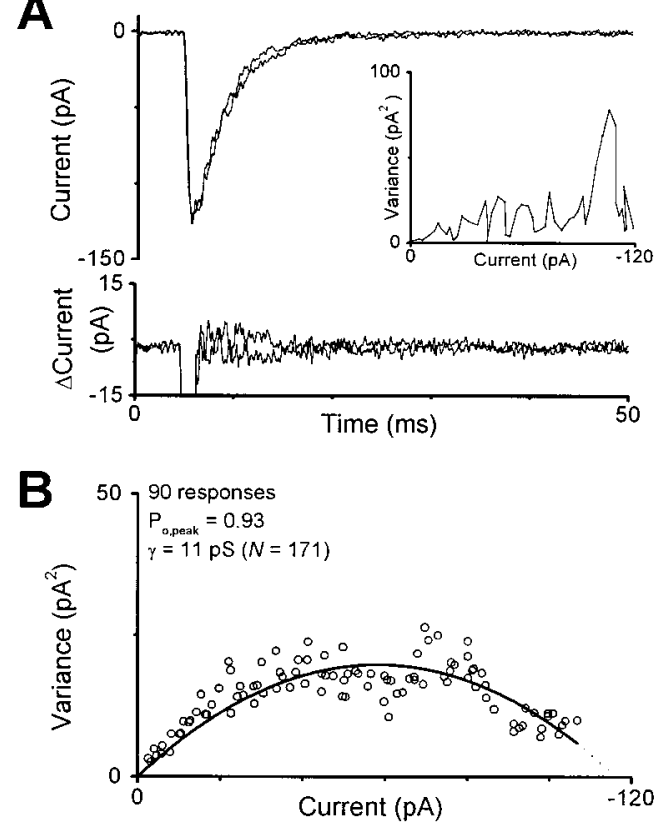
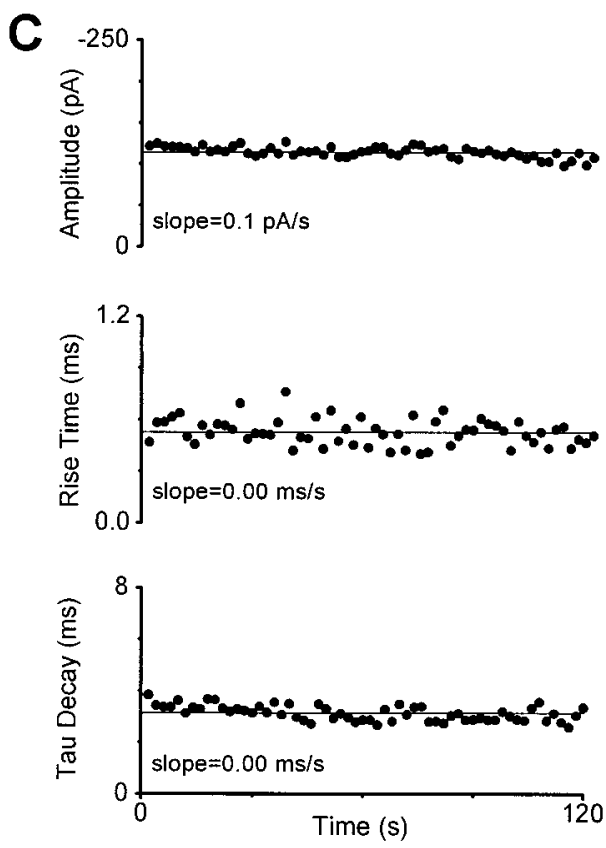

A

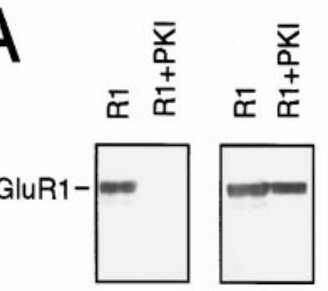

S845-P GluR1
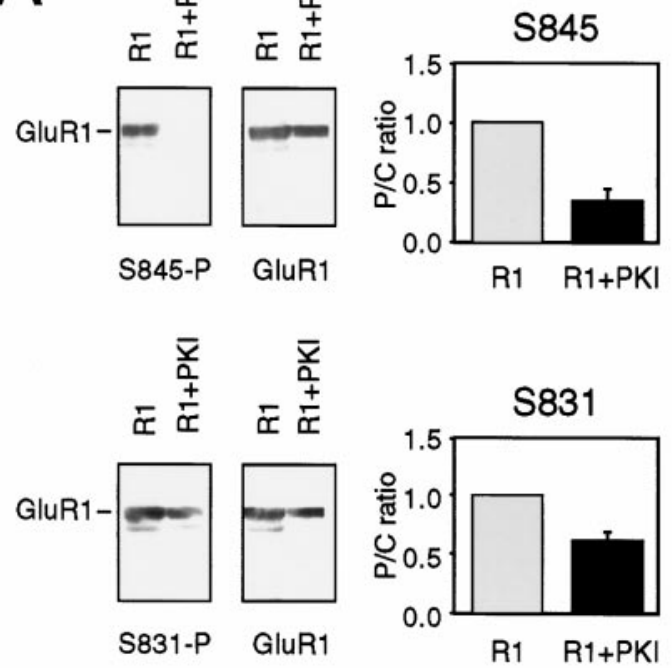

B
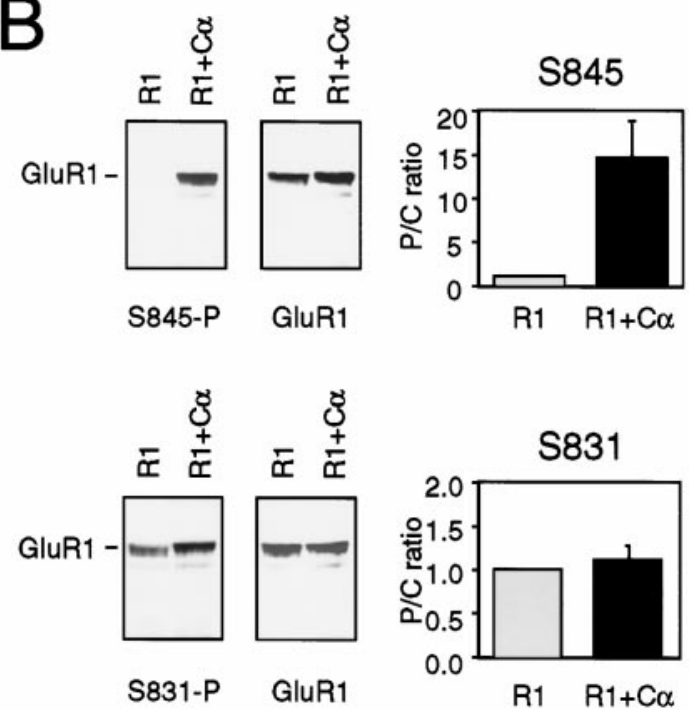

Figure 4. Control of GluR1 Ser845 phosphorylation by cotransfection with cDNA encoding C $\alpha$-PKA and PKI. A, Top panel, Representative immunoblot showing reduction in GluR1 Ser845 phosphorylation with cotransfection of a cDNA encoding the peptide inhibitor PKI. The same immunoblot was probed with an antibody that recognizes phosphorylated Ser845, and stripped and reprobed using an antibody against GluR1. $P / C$ is the ratio of S845-P signal intensity normalized to GluR1 C-terminal antibody signal intensity (total GluR1) for PKI or PKA treatment versus control and illustrates the reduction in basal phosphorylation by the PKI vector $(p<0.05)$. For comparison, a P/C ratio of 1.0 is shown for the control lane $(R 1)$. Bottom panel, Immunoblot showing that cotransfection with PKI also reduces Ser831 phosphorylation $(p<0.05)$. B, Top panel, Immunoblot showing enhancement of GluR1 Ser845 phosphorylation with cotransfection of cDNA encoding C $\alpha$-PKA. An antibody selective for phosporylated-Ser845 $(S 845-P)$ was used to probe the blot, and the same blot subsequently was stripped and reprobed with a GluR1-selective antibody (see Materials and Methods). The bar graph to the right shows the quantification of the $\mathrm{C} \alpha$-PKA-induced enhancement of Ser845 phosphorylation as the ratio of immunodetected phosphorylated GluR1 to total GluR1; error bars are SEM ( $p<0.05$; paired $t$ test). Control bars $(R 1)$ were set at 1.0 for comparison. The level of basal phosphorylation in $A$ and $B$ are similar and appear different because of the different exposure times for the ECF analysis. Bottom panel, Immunoblot and analysis showing the lack of effect on phosphorylation of GluR1 Ser831 by cotransfection with C $\alpha$-PKA.

responses in excised membrane patches from HEK 293 cells transiently expressing GluR1 (Fig. $3 A$ ). Application of a maximal concentration of glutamate $\left(10 \mathrm{~mm} ; \mathrm{EC}_{50} 0.5 \mathrm{~mm}\right)$ (Wahl et al., 1998) to outside-out patches evoked fast-activating current responses that desensitized rapidly and profoundly (Table 2) and reversed in the absence of spermine at a membrane potential of
$+1 \mathrm{mV}(n=3$; corrected for $+9 \mathrm{mV}$ measured junction potential). As shown in Figure $3 C$, the glutamate-evoked currentresponse waveform was stable through many agonist applications at a 2 sec interval. Typically 20-300 wild-type GluR1 current responses (mean 63) were recorded over several minutes from outside-out patches. Holding potential was $-60 \mathrm{mV}$. 


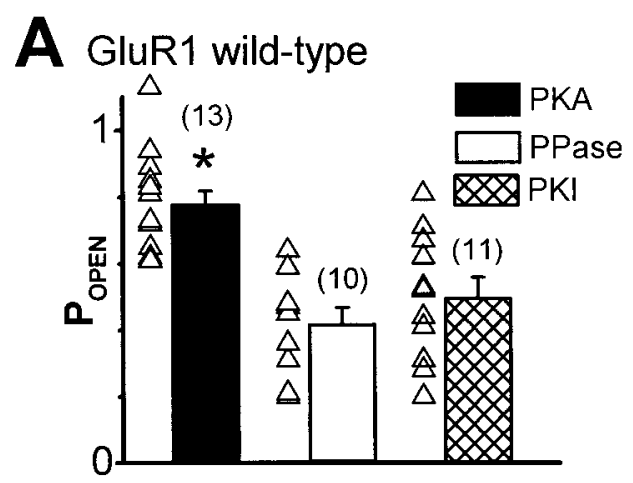

B GluR1 S845A
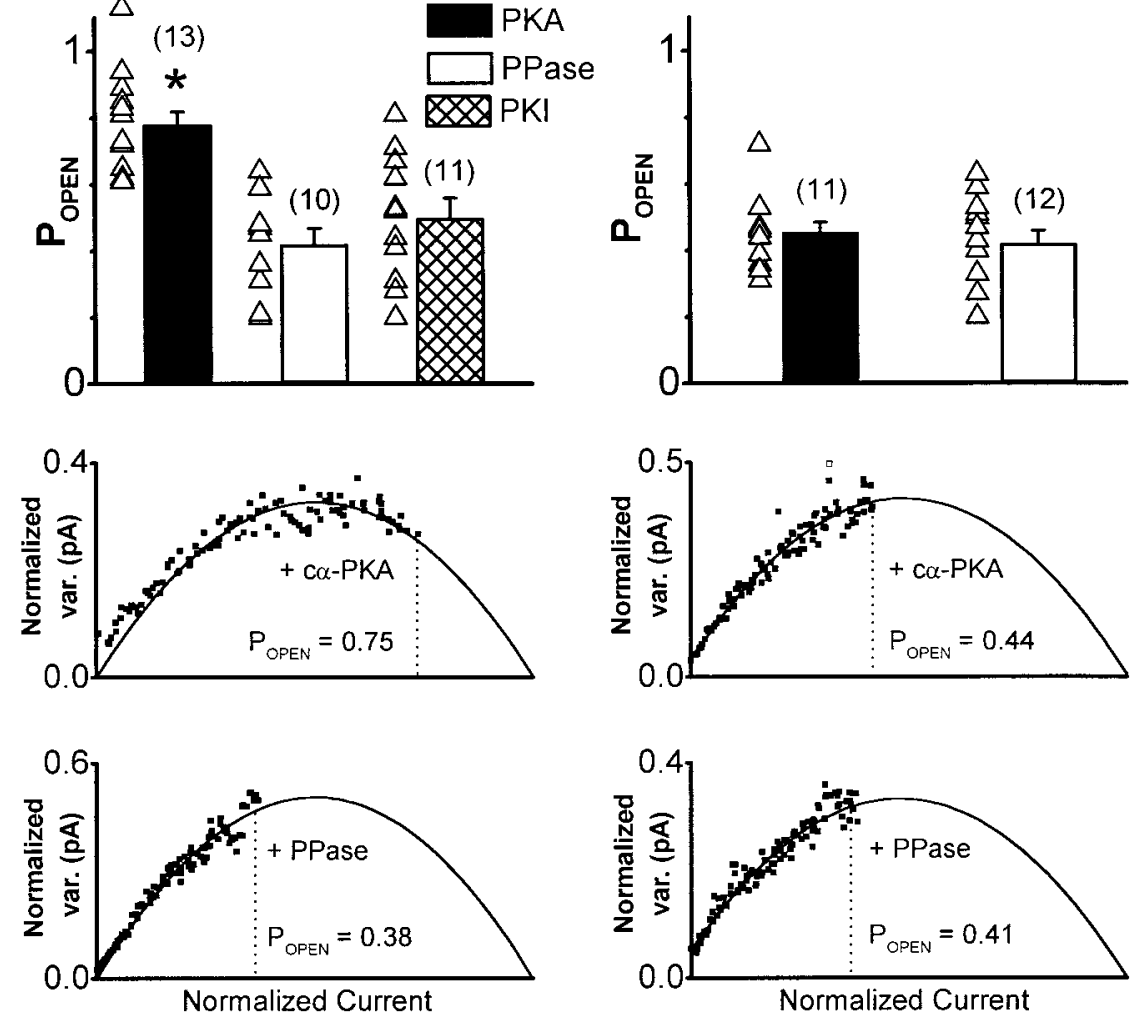
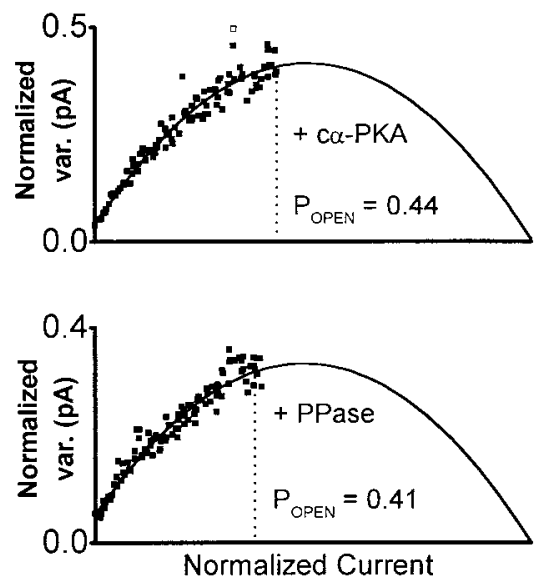

C GluR1 S831A
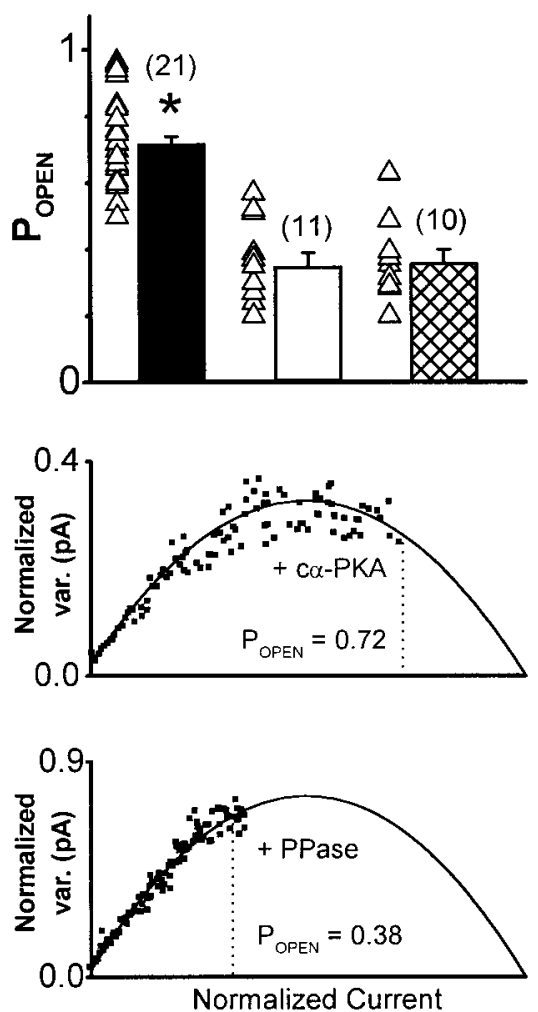

Figure 5. The catalytic subunit $\mathrm{C} \alpha$-PKA increases and calcineurin decreases GluR1 $P_{\mathrm{O}}$, PEAK.$A$, Top panel, The mean $P_{\mathrm{O} \text {, PEAK }}$ was determined using values from $i$ and $N$ from fits of current-variance relationships for 30-300 responses to $10 \mathrm{mM}$ glutamate recorded in excised patches with C $\alpha$-PKA (labeled $P K A$ ) or calcineurin (labeled PPase) added to the pipette solution (Table 1). PKI indicates cells transfected with a cDNA encoding a PKI-GFP fusion protein and recorded with a low $\mathrm{Ca}^{2+}$ internal solution without PKA or calcineurin added (Table 1). Symbols show values from individual membrane patches, and bars show mean $P_{\mathrm{O} \text {, PEAK}}$; error bars are $\mathrm{SEM}$, and the number of patches is indicated in parentheses. $P_{\mathrm{O}, \mathrm{PEAK}}$ is calculated from the fitted values for $N$ and $i$, and therefore estimates occasionally exceed 1.0. Normalized current-variance plots were averaged for all patches containing $\mathrm{C} \alpha$-PKA (middle panel) or calcineurin (bottom panel). Continuous lines show fitted normalized variance from Equation 3 . $B$, $C$, The mean $P_{\mathrm{O}}$, PEAK was determined using fitted values of $i$ and $N$ from the current-variance relationship for responses to $10 \mathrm{~mm}$ glutamate recorded under the same conditions as above for $(B)$ GluR1(S845A) or $(C)$ GluR1(S831A) with $\mathrm{C} \alpha$-PKA or calcineurin added to the patch pipette, respectively. For all panels, asterisks indicate $p<0.05$ using Student's $t$ test for GluR1(S845A) and ANOVA for GluR1(S831A) and wild-type GluR1 $(A)$. When no significant difference was found, the power to detect a difference of 0.2 ranged between 0.8 and 0.9 .

To evaluate the mechanism underlying the ability of PKA to potentiate recombinant GluR1 function, we determined the GluR1 response time course, weighted mean single-channel conductance, rate of desensitization, and the probability of receptor opening when the purified catalytic subunit $\mathrm{C} \alpha$-PKA was included in the pipette; some cells were also cotransfected with cDNA encoding $\mathrm{C} \alpha$-PKA. Measurements under these conditions were compared with those obtained from cells cotransfected with a cDNA encoding the PKA inhibitor peptide PKI without $\mathrm{C} \alpha$ PKA added to the pipette solution. The effects of PKI and $\mathrm{C} \alpha$-PKA cotransfection on GluR1 phosphorylation were assessed by immunoblot analysis using phosphorylation site-specific antibodies (Fig. 4) (Mammen et al., 1997). Cotransfection of PKI with GluR1 significantly reduced the phosphorylation of the C-terminal PKA phosphorylation site Ser845 (0.36 \pm 0.09-fold of basal phosphorylation measured when GluR1 was transfected alone, $n=7, p<0.001$; paired $t$ test). Ser831 phosphorylation also unexpectedly decreased with PKI cotransfection $(0.60 \pm 0.09$ fold of basal phosphorylation, $n=7$; $p<0.005$; paired $t$ test). These changes are unlikely to reflect changes in GluR1 expression levels by PKI, because the expression of GluR1 was comparable in cells expressing GluR1 with or without PKI. The change in Ser831 phosphorylation may be caused by downregulation of signal transduction cascades that maintain basal Ser831 phosphorylation. Cotransfection of HEK 293 cells with GluR1 and $\mathrm{C} \alpha$-PKA significantly increased phosphorylation of GluR1 at Ser845 (14.5 \pm 4.2-fold increase; $n=7)$, compared with basal phosphorylation observed when GluR1 was transfected alone (paired $t$ test: $p<0.05$ ) (Fig. 4). The effect of $\mathrm{C} \alpha$-PKA on phosphorylation of GluR1 was specific to Ser845, because there was no significant change in phosphorylation at Ser831 (1.1 \pm 0.2 -fold change compared with basal phosphorylation; $n=7 ; p>$ 0.5 ; paired $t$ test); the increase in Ser845 phosphorylation by $\mathrm{C} \alpha$ PKA was almost completely eliminated when Ser845 was mutated to alanine (93 $\pm 3 \%$ inhibition of phosphorylation, $n=5)$.

Nonstationary variance analysis of homomeric GluR1 macroscopic current responses (Fig. 3) to rapid application of maximally effective glutamate suggests that inclusion of $\mathrm{C} \alpha$-PKA in the patch pipette solution has little effect on weighted mean unitary current of wild-type GluR1 measured at $-60 \mathrm{mV}$ (Table 2). Likewise $\mathrm{C} \alpha$-PKA has no effect on GluR1 response time course in excised membrane patches (Table 2). However, Figure $5 A$ shows that $P_{\mathrm{O}, \mathrm{PEAK}}$ is high in the presence of $\mathrm{C} \alpha$-PKA and ATP compared with cells cotransfected with PKI or with cal- 
Table 3. Structural determinants of effects of PKA and calcineurin on GluR1 function

\begin{tabular}{llllll} 
Mutant GluR1 & $\begin{array}{l}\gamma_{\text {CHORD }} \\
(\mathrm{pS})\end{array}$ & $\begin{array}{l}10-90 \% \text { rise time } \\
(\mathrm{msec})\end{array}$ & $\begin{array}{l}\operatorname{tau}_{\text {DECAY }} \\
(\mathrm{msec})\end{array}$ & $\begin{array}{l}\text { SS/peak } \\
\text { ratio }\end{array}$ & $N$ \\
\hline GluR1(S845A) + PKA & $12 \pm 1$ & $0.42 \pm 0.02$ & $2.10 \pm 0.19$ & 0.04 & 11 \\
GluR1(S845A) + calcineurin & $12 \pm 1$ & $0.35 \pm 0.02$ & $2.01 \pm 0.27$ & 0.02 & 12 \\
GluR1(S831A) + PKA & $14 \pm 1$ & $0.47 \pm 0.09$ & $2.52 \pm 0.10$ & 0.02 & 24 \\
GluR1(S831A) + calcineurin & $14 \pm 2$ & $0.40 \pm 0.01$ & $2.37 \pm 0.24$ & 0.04 & 11 \\
GluR1(S831A) + PKI & $12 \pm 1$ & $0.35 \pm 0.02$ & $2.07 \pm 0.09$ & 0.03 & 11
\end{tabular}

Measurements (mean \pm SEM) were made from excised membrane patches held under voltage clamp at $-60 \mathrm{mV}$ and obtained from cells transfected with GluR1(S845A) or GluR1(S831A) cDNA. Rise time and tau the five patches with the fastest rise times; tau ${ }_{\text {DECAY }}$ was determined as described in Table 2. $N$ is the number of patches. SS/peak ratio refers to the ratio of steady-state current to the peak current (see Table 2 legend); statistical tests were not performed on this ratio given the ambiguity in measuring the low amplitude steady-state current. Measurements made for each mutant were not significantly different $(p>0.05)$ by ANOVA. Power to detect a $4.7 \mathrm{pS}, 0.25 \mathrm{msec}$, or $2.5 \mathrm{msec}$ difference in $\gamma$, rise time, tau ${ }_{\mathrm{DECAY}}$ at $\alpha=0.05$ ranged between 0.8 and 0.9 .

cineurin added to the patch pipette. Measurements of $P_{\mathrm{O}, \mathrm{PEAK}}$ from current responses to maximal concentrations of glutamate are clustered with a mean of $0.78 \pm 0.04(n=13)$ (Fig. $5 A)$ when purified $\mathrm{C} \alpha$-PKA is included in the pipette; $P_{\mathrm{O} \text {,PEAK }}$ was also high $(0.62 \pm 0.04 ; n=6$; data not shown $)$ in patches excised from cells cotransfected with a cDNA encoding $\mathrm{C} \alpha$-PKA. These values are similar to the maximum single-channel $P_{\text {O,PEAK }}$ value predicted for homomeric GluR1 receptors (0.80; Eq. 7) using the mean number of opening periods per burst $(1.22 ; n=7$ patches $)$, the mean open period duration $(0.47 \mathrm{msec})$ determined from a composite histogram of all openings in all patches (see Fig. 7), and the mean burst length (Table 2 ). By contrast, $P_{\mathrm{O}, \mathrm{PEAK}}$ was significantly lower in cells expressing the PKA inhibitor peptide PKI and lacking catalytic subunit $\mathrm{C} \alpha$-PKA in the pipette $(0.50 \pm$ $0.06 ; n=11$ ) (Fig. $5 A$ ). The somewhat increased variability of $P_{\text {O,PEAK }}$ in PKI transfected cells may reflect a variable level of Ser831 basal phosphorylation, which can also increase $P_{\mathrm{O} \text {,PEAK }}$ (T. G. Banke and S. F. Traynelis, unpublished data). Inclusion of purified calcineurin and its co-activators (100 nM $\mathrm{Ca}^{2+}$,calmodulin) in the pipette solution for patches obtained from cells transfected with PKI also showed a low $P_{\text {O,PEAK }}(0.42$ $\pm 0.05 ; n=10$ ). Figure $5 A$ (bottom panels) compares the pooled normalized current-variance plots for responses from different patches with either $\mathrm{C} \alpha$-PKA or calcineurin plus its coactivators included in the pipette. These current-variance curves illustrate the predicted parabolic relationship and more clearly demonstrate the difference in $P_{\mathrm{O} \text {,PEAK}}$.

To determine whether PKA modifies receptor function through ATP-dependent phosphorylation, we performed control experiments in which we included $\mathrm{C} \alpha$-PKA in the patch pipette together with AMP-PNP, a non-hydrolyzable analog of ATP. Cells were cotransfected with GluR1 and PKI to reduce basal phosphorylation of Ser845; we assume that all endogenously expressed PKI is rapidly washed out from our patch. Inclusion of $\mathrm{C} \alpha$-PKA and the nonhydrolyzable ATP analog in the patch pipette was associated with a reduced $P_{\text {O,PEAK }}$ value $(0.40 \pm 0.06$; $n=11)$ when compared with $\mathrm{C} \alpha$-PKA plus ATP $(p<0.001)$. This result is consistent with the idea that $\mathrm{C} \alpha$-PKA mediates its effects on receptor function through ATP-dependent phosphorylation of GluR1 rather than association with an intracellular portion of the receptor.

\section{Structural determinants of control of recombinant GluR1 Po,PEAK by PKA}

Ser845 and Ser831 are two C-terminal residues that are unique to GluR1 compared with other AMPA receptor subunits (Fig. 1) and have been biochemically identified as substrates for phosphorylation. Roche et al. (1996) and Barria et al. (1997) have sought to link these phosphorylation sites to functional effects of the kinases by showing that exchange of Ser845 and Ser831 to alanine blocks the potentiating effects of PKA and CAMKII on GluR1 responses, respectively. To test whether either of these two residues might control the effects of PKA on $P_{\text {O,PEAK }}$ described here, we recorded current responses from GluR1(S845A) and GluR1(S831A) during rapid application of maximal concentrations of glutamate. Analysis of the response time course and current-variance relationship for GluR1(S845A) suggests that inclusion of $\mathrm{C} \alpha$-PKA in the patch pipette had no effect on $P_{\text {O,PEAK }}$ (Fig. 5B), weighted mean unitary current, rise time, or the time course for receptor desensitization in excised membrane patches when compared with recordings made with calcineurin (Table 3). Thus, the substitution S845A in GluR1 blocks the enhancement of $P_{\mathrm{O}, \mathrm{PEAK}}$ by PKA without altering other response characteristics. By contrast, PKA was still able to enhance $P_{\text {O,PEAK }}$ of the GluR1(S831A) mutant compared with both PKI transfected cells and patches with calcineurin included in the pipette solution, suggesting that the effects of PKA do not reflect phosphorylation of Ser831 (Fig. $5 C$ ) or indirect effects of other kinases that act on Ser831. These results are consistent with biochemical studies that show that recombinant and native GluR1 Ser845 but not Ser831 is phosphorylated in vitro and in vivo by PKA (Fig. 4) (Roche et al., 1996; Mammen et al., 1997).

\section{Effects of PKA and calcineurin on single-channel currents}

Both recombinant and native AMPA receptors have previously been shown to arise from multiple conductance levels (Wyllie et al., 1993; Swanson et al., 1997; Dingledine et al., 1999), which complicates the relationship between response amplitude, variance, and $P_{\mathrm{O}, \mathrm{PEAK}}$. For example, a change in relative opening frequency of any conductance level will change the relative macroscopic current as well as the variance. Moreover, the presence of multiple conductance levels means that current variance will still exist even for $P_{\mathrm{O} \text {,PEAK }}$ values of 1.0. To evaluate the complex contribution that changing sublevel occupancy might make to our measurements of $P_{\mathrm{O} \text {,PEAK }}$ from Equations 1-5, we sought to determine the sublevel amplitudes with single-channel analysis of recombinant GluR1 receptors activated by application of a submaximal concentration of glutamate.

Figure 6 shows examples of glutamate-activated homomeric GluR1 channel openings recorded when either $\mathrm{C} \alpha$-PKA or calcineurin plus its coactivators are included in the pipette. We 
A + C $\alpha$ PKA

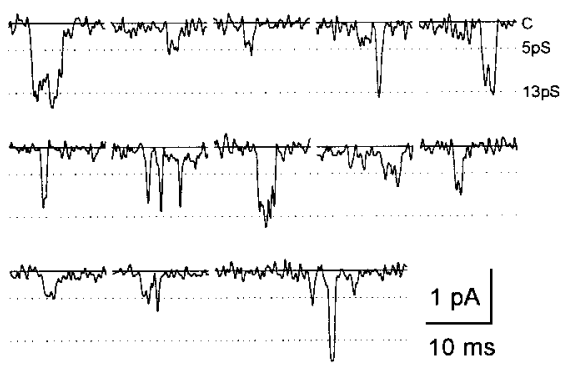

C +Calcineurin
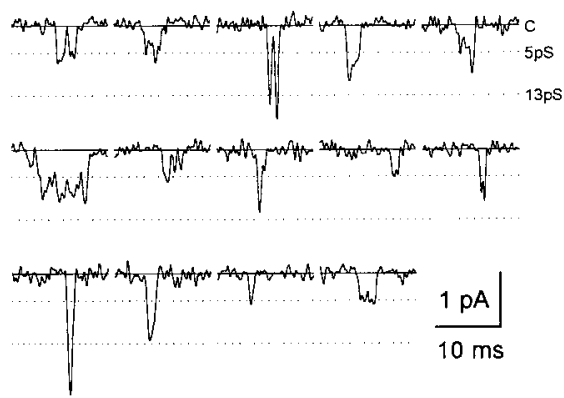

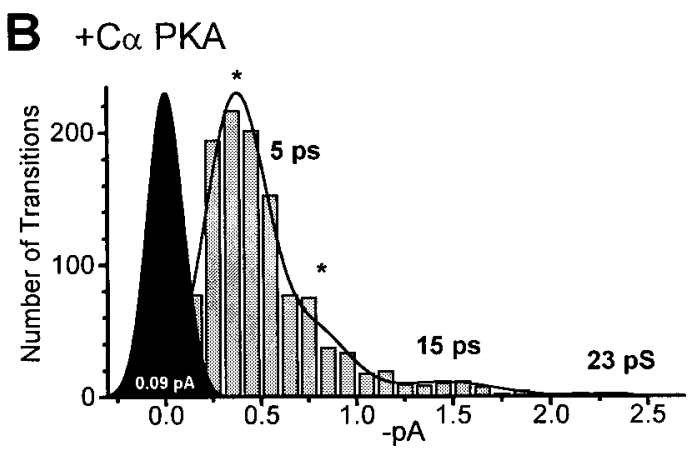

D +Calcineurin

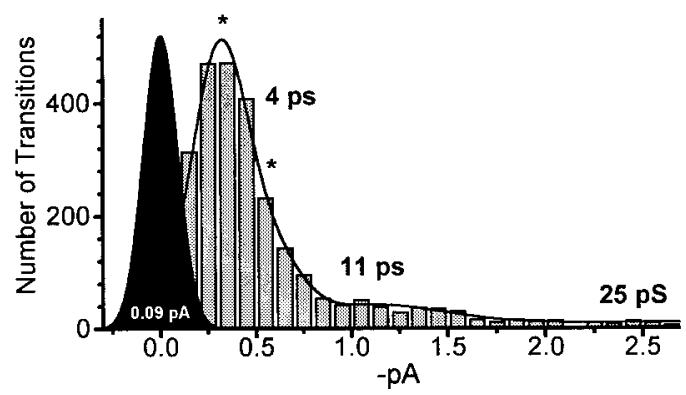

Figure 6. Homomeric GluR1 subconductance levels activated by glutamate. $A, C$, Examples are shown for unitary currents recorded in response to $10 \mu \mathrm{M}$ glutamate from outside-out patches containing recombinant homomeric GluR1 receptors with either $\mathrm{C} \alpha$-PKA $(A)$ or calcineurin plus its coactivators $(C)$ included in the patch pipette. Singlechannel currents were recorded at -100 $\mathrm{mV}$, filtered at $1 \mathrm{kHz}$, digitized at 20 $\mathrm{kHz}$. Broken lines show the mean fitted sublevel conductances assuming a reversal potential of $0 \mathrm{mV} ; c$ indicates the closed level. $B, D$, Composite amplitude histograms from all patches are shown with mean fitted sublevels indicated, as well as the closed point distribution ( filled) scaled to the fitted peak of the lowest conductance level. In both situations, four Gaussian components were required to fit the histogram, with two components under $10 \mathrm{pA}$ (shown as asterisks); this second subconductance level is more evident in PKA. The solid line is a fit to this composite curve. Fitted individual unitary current (in pA), SD (in pA), and relative proportions for $\mathrm{C} \alpha$-PKA were $i_{1}=-0.4, w_{1}=0.75$, $\mathrm{SD}_{1}=0.17, i_{2}=-0.8, w_{2}=0.18, \mathrm{SD}_{2}=$ $0.2, i_{3}=-1.5, w_{3}=0.06, \mathrm{SD}_{3}=0.26$, $i_{4}=-2.3, w_{4}=0.01, \mathrm{SD}_{4}=0.26$ and for calcineurin were $i_{1}=-0.3, w_{1}=0.63, \mathrm{SD}_{1}=0.14, i_{2}=-0.6, w_{2}=0.12, \mathrm{SD}_{2}=0.13, i_{3}=-1.0, w_{3}=0.17$, $\mathrm{SD}_{3}=0.43, i_{4}=-2.5, w_{4}=0.08, \mathrm{SD}_{4}=0.79$. The weighted means (see Table 4 legend) of the two low conductance states are indicated, and the individual components are shown with an asterisk. Nine (PKA) and 57 (Calcineurin) individual transitions with an amplitude between -3 and $-5 \mathrm{pA}$ were omitted from the fitting process.

analyzed these responses by fitting a filtered step-response function to all apparent transitions between closed and open sublevels. Currents chosen for analysis were between -0.2 and $-4.0 \mathrm{pA}$ in amplitude and had durations longer than 0.12 msec. Openings were brief in duration with fitted time constants for distributions of the mean open period, mean burst length, and mean intraburst gap times (data not shown) that were similar to those reported for GluR4(flip) (Fig. 7). The mean burst length (Table 2) is also similar to the relaxation time constant $(0.8-1.1 \mathrm{msec})$ observed for GluR1 receptors in response to brief pulses of glutamate (Mosbacher et al., 1994; Partin et al., 1996). Addition of C $\alpha$-PKA or calcineurin plus its coactivators did not alter the mean open period or burst length of GluR1 unitary currents (Table 2, Fig. 7), consistent with the lack of effect of these treatments on the response time course (Table 2).

Inspection of amplitude histograms constructed from analysis suggests that homomeric GluR1 receptors open to at least three distinct sublevels in response to glutamate, as has been reported for native (Cull-Candy and Usowicz, 1987; Jahr and Stevens, 1987) and recombinant glutamate receptors (Swanson et al., 1996, 1997; Derkach et al., 1999). Composite amplitude histograms constructed from our lowest noise patches (Fig. $6 C, D$ ) were best fit by four Gaussian components (Colquhoun and Sigworth, 1995), perhaps suggesting that more than one subconductance level may exist below $10 \mathrm{pS}$ [see also Swanson et al. (1996)]. The infrequent openings above $-2 \mathrm{pA}$ made determination of the amplitude of the largest conductance level ambiguous. Accordingly, we fit the large amplitude unitary current range ( -2 to -4 pA) with a single, broad Gaussian component. Table 4 summarizes the three main sublevel amplitudes and their relative proportions obtained from fits to histograms of glutamate-activated single-channel currents constructed from individual patches when
$\mathrm{C} \alpha$-PKA or calcineurin were included in the pipette. There was no significant difference in the weighted mean unitary current predicted from these patches, consistent with our conclusion from variance analysis of the macroscopic currents (Table 2). These data together suggest that PKA phosphorylation of GluR1 is not associated with a large change in single-channel conductance or open duration. Similar conductance levels were observed using 10 $\mu \mathrm{M}$ quisqualate to activate GluR1 in outside-out patches with PKA or calcineurin included in the pipette (data not shown; $n=6$ ).

When three or more sublevels exist, there are multiple combinations of sublevel open probabilities that can generate any given current-variance curve. In this situation the total $P_{\mathrm{O}, \mathrm{PEAK}}$ for these different proportions of sublevel openings (i.e., the sum of the various sublevel open probabilities) will not necessarily match the $P_{\mathrm{O} \text {,PEAK }}$ estimated from Equations $1-5$. Therefore, we used the GluR1 sublevel amplitudes determined above to evaluate all possible combinations of sublevel open probabilities that could yield the current-variance curves that we observe with calcineurin or $\mathrm{C} \alpha$-PKA included in our pipette solution (Fig. $5 A$ ). This analysis assumes that the conductance levels (but not their relative opening frequencies) are the same in $10 \mu \mathrm{M}$ and $10 \mathrm{~mm}$ glutamate. Figure $8 B$ shows a three-dimensional plot of the solutions of Equation 6 to the current-variance relationships (Fig. $8 A$ ) that are representative of the results obtained with $\mathrm{C} \alpha$-PKA or calcineurin included in the internal solution. This plot shows that the full range of possible $P_{\mathrm{O}, \mathrm{PEAK}}$ values that account for our data obtained with $\mathrm{C} \alpha$-PKA and calcineurin do not overlap, and thus we conclude that homomeric GluR1 $P_{\mathrm{O} \text {,PEAK }}$ values are distinct for PKA and calcineurin. This result strengthens our interpretation that $\mathrm{PKA}$ increases receptor $P_{\mathrm{O}, \mathrm{PEAK}}$ relative to calcineurin. 

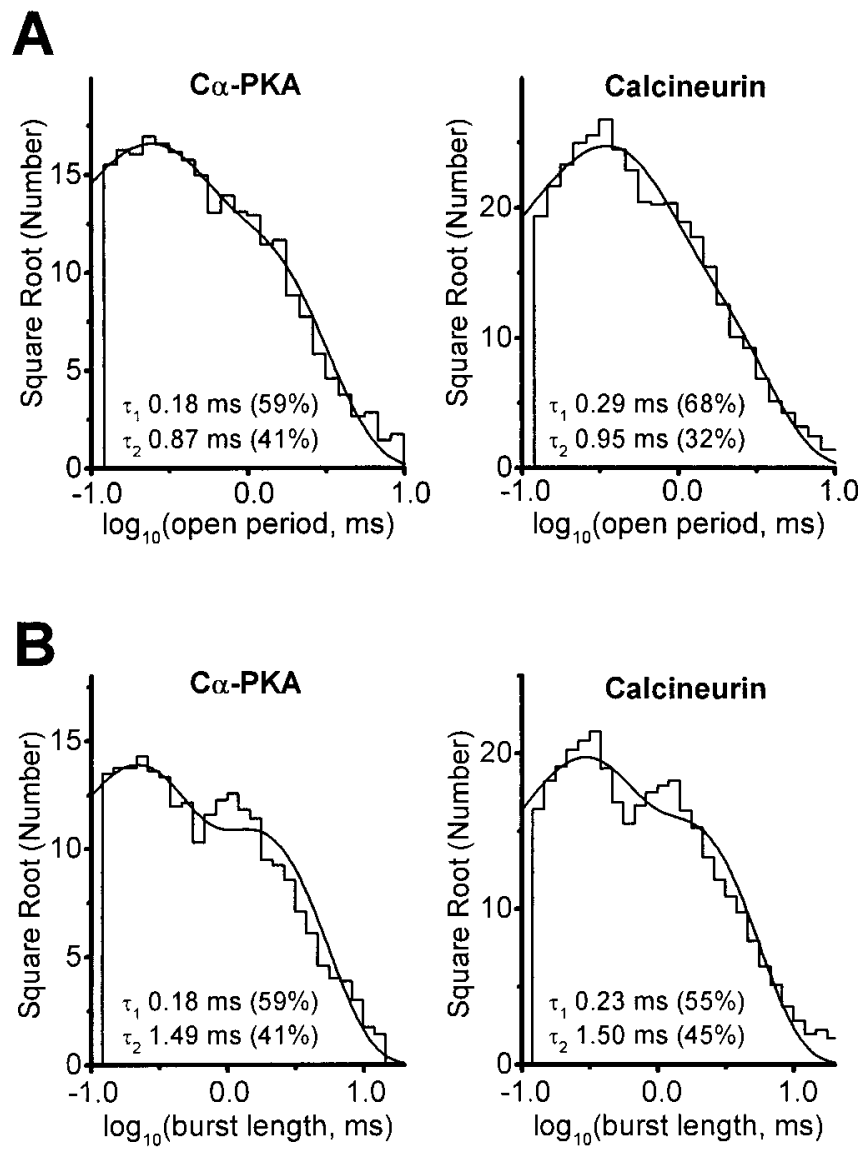

Figure 7. Homomeric GluR1 open period and burst duration histograms. $A$, The composite open period histograms from all patches with $\mathrm{C} \alpha$-PKA or calcineurin plus its coactivators included in the pipette solution were fitted by the sum of two exponential components. Open periods are shown between 0.12 and $10 \mathrm{msec} ; 13$ and 32 open periods greater than $10 \mathrm{msec}$ in duration were omitted for PKA and calcineurin, respectively. $B$, The composite burst length histograms from all patches with $\mathrm{C} \alpha$-PKA or calcineurin plus its coactivators included in the pipette solution were fitted by the sum of two exponential components. Bursts durations were determined using a $T_{\text {CRIT }}$ of $1.0 \mathrm{msec}$ and are shown between 0.12 and $20 \mathrm{msec} ; 19$ and 28 burst durations greater than $20 \mathrm{msec}$ were omitted for PKA and calcineurin, respectively.

\section{DISCUSSION}

The most important finding of this study is that phosphorylation of GluR1 Ser845 by PKA appears to increase the peak open probability of the receptor. This result is in contrast to the effects of CAMKII, which phosphorylates Ser831 to increase GluR1 unitary conductance (Barria et al., 1997; Derkach et al., 1999) and possibly postsynaptic AMPA receptor conductance during LTP (Barria et al., 1997; Benke et al., 1998). Thus, the same portion of the $\mathrm{C}$ terminal of the GluR1 molecule (residues 831-845) controls distinct determinants of channel function: open probability and single-channel conductance. Our results may provide an explanation for some forms of plasticity at synapses where AMPA receptors contain GluR1, and they further suggest that synaptic plasticity that proceeds through PKA control of $P_{\mathrm{O}, \mathrm{PEAK}}$ can tune postsynaptic responsiveness without altering response kinetics. Moreover, increased fluctuations in postsynaptic current amplitude that accompany the reduction in glutamate receptor $P_{\text {O,PEAK }}$ will increase noise in the CNS, which may hold implications for information processing (Traynelis and Jaramillo, 1998).
Table 4. Homomeric GluR1 subconductance levels

\begin{tabular}{|c|c|c|c|c|c|c|c|c|}
\hline \multirow{2}{*}{$\begin{array}{l}\text { Wild-type } \\
\text { GluR1 }\end{array}$} & \multicolumn{2}{|l|}{$\gamma 1$} & \multicolumn{2}{|l|}{$\gamma 2$} & \multicolumn{2}{|l|}{$\gamma 3$} & \multicolumn{2}{|c|}{$\gamma_{\text {NOISE }}$} \\
\hline & $(\mathrm{pS})$ & $(\%)$ & $(\mathrm{pS})$ & $(\%)$ & $(\mathrm{pS})$ & $(\%)$ & $(\mathrm{pS})$ & $N$ \\
\hline$+\mathrm{PKA}$ & 5 & 86 & 14 & 12 & 20 & 2 & 8.3 & 7 \\
\hline+ Calcineurin & 4 & 66 & 11 & 27 & 25 & 7 & 11.8 & 6 \\
\hline
\end{tabular}

Chord subconductance values $(\gamma)$ were determined from the amplitude histogram constructed from time course-fitted unitary current amplitudes assuming a reversal potential of $0 \mathrm{mV}$. Fits of three Gaussian components were made to the amplitude histogram from each patch using maximum likelihood. Single-channel currents were recorded as described in Materials and Methods. $\gamma_{\text {NOISE }}$ is the mean weighted chord conductance calculated from these sublevels (Cull-Candy et al., 1988) according to:

$$
\gamma_{\mathrm{NOISE}}=\sum_{J=1}^{k}\left(w_{\mathrm{J}} \gamma_{\mathrm{J}}^{2}\right) /\left(w_{\mathrm{J}} \gamma_{\mathrm{J}}\right)
$$

where is $w_{\mathrm{J}}$ is the proportion of $k$ sublevels, each with conductance $\gamma_{\mathrm{J}} . N$ is the number of patches. The standard deviation of the Gaussian component describing $\gamma 3$ is broad, perhaps because of the presence of rarely accessed large conductance states. In addition, $\gamma 1$ may reflect the average of two smaller sublevels that were difficult to distinguish in all but our lowest noise patches.

\section{Comparison of results with previous work}

Previous studies have shown that PKA can enhance neuronal AMPA receptor equilibrium response amplitude (Knapp et al., 1990), slow AMPA receptor rundown (Wang et al., 1991; Rosenmund et al., 1994), increase channel opening frequency without changing single-channel conductance (Greengard et al., 1991), and potentiate GluR1 receptor responses without changing their time course (Roche et al., 1996). Moreover, forskolin also potentiates postsynaptic AMPA receptor function, presumably through activation of PKA (Chavez-Noriega and Stevens, 1992). Our results are consistent with these findings, as well as the suggestion by Knapp et al. (1990) that PKA increases the AMPA receptor equilibrium open probability. Moreover, our data also support the idea that recombinant and native AMPA receptors can open with a high probability $(>0.5)$ when maximally activated by the endogenous agonist glutamate (Hestrin, 1992; Raman and Trussell, 1995; Spruston et al., 1995; Hausser and Roth, 1997; Irizarry et al., 1998). However, we do not observe a PKA-induced change in the mean channel open time or burst length for recombinant GluR1, as previously noted for neuronal AMPA receptors (Greengard et al., 1991). This discrepancy may reflect subunit composition or differences between our heterologous expression system and neurons. Our finding that S845A abolishes the effect of PKA on recombinant GluR1 fits well with data showing that this residue can be phosphorylated in vitro by $\mathrm{C} \alpha$-PKA (Roche et al., 1996), in brain slices by forskolin activation of adenylyl cyclase (Mammen et al., 1997), and in HEK 293 cells cotransfected with GluR1 and C $\alpha$-PKA (Fig. 4).

Although our measurements are consistent with previous findings, two potential sources of artifact deserve mention. First, Rosenmund et al. (1998) have shown that antagonist-bound AMPA receptors in the absence of desensitization sequentially pass through three subconductance levels as they bind and unbind agonist. Although this study suggests that the response onset may have a sublevel composition that changes with time, the high concentration of agonist used here $\left(20 \times \mathrm{EC}_{50}\right)$ should induce activation of the fully liganded state of GluR1 within the brief rising phase of the response, which was omitted from our variance analysis. Second, any change in the sublevel composition of the response during desensitization could alter the current variance and invalidate the use of Equations 1-6. However, we obtained 

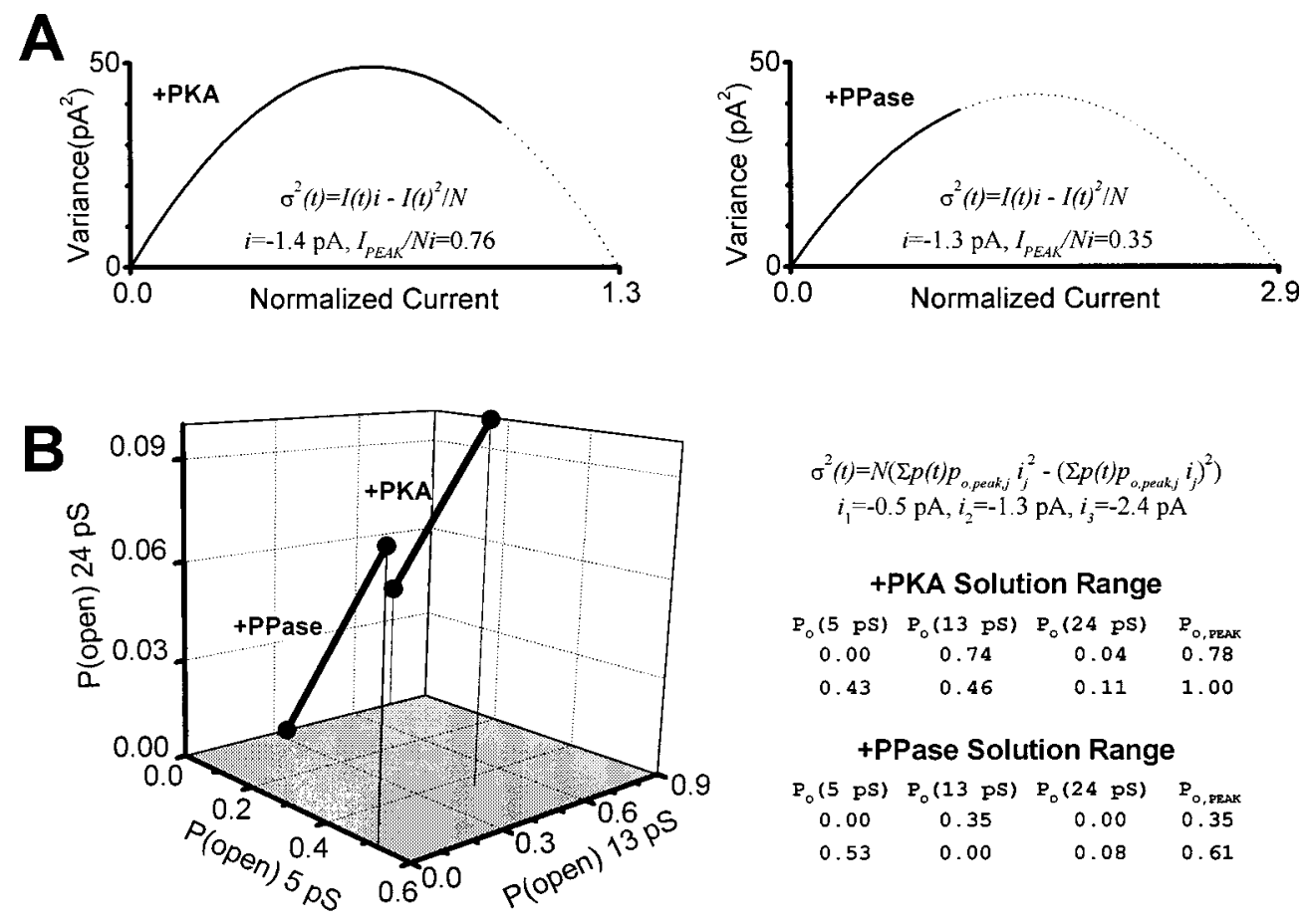

$$
\begin{aligned}
\sigma^{2}(t) & =N\left(\Sigma p(t) p_{o, p e a k_{j} j} i_{j}^{2}-\left(\Sigma p(t) p_{o, p e a k, j} i_{j}\right)^{2}\right) \\
i_{1} & =-0.5 \mathrm{pA}, i_{2}=-1.3 \mathrm{pA}, i_{3}=-2.4 \mathrm{pA}
\end{aligned}
$$

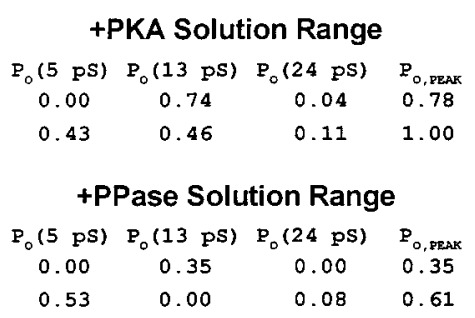

Figure 8. Changing subconductance level proportions and $P_{\mathrm{O}}$, PEAK. $A$, Equation 1 was used to generate theoretical current-variance curves $(-100$ $\mathrm{mV}$ ) with properties of our responses with PKA or calcineurin in the patch pipette. The unitary current and $P_{\mathrm{O}}$, PEAK values are indicated and reflect the pooled mean of data from wild-type GluR1 and GluR1(S831A) receptors. $B$, Equation 6 was used to calculate a theoretical current-variance relationship and compare it with the relationships shown in $A$. Different combinations $\left(2 \times 10^{9}\right)$ of the 5,13 , and $24 \mathrm{pS}$ conductance levels (varied between 0 and 1 in steps of 0.001 or 0.0005 ) were compared with the current-variance curves for GluR1 responses recorded with $\mathrm{C} \alpha$-PKA or calcineurin included in the patch pipette. The two lines show the set of solutions for PKA and calcineurin. Any combinations of sublevel open probabilities along these lines can produce a current-variance curve indistinguishable from that produced by Equation 1 when fitted to our idealized data in $A . P_{\mathrm{O}}$, PEAK was calculated as the sum of the sublevel peak open probabilities and varied across the set of solutions for both calcineurin and PKA.

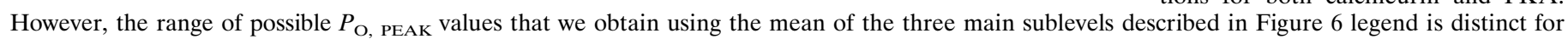
PKA versus calcineurin.

similar results when we fit current-variance curves constructed from different fractions of the response decay, suggesting that weighted mean unitary current does not fluctuate during desensitization beyond our limits of detection $(\sim 0.3 \mathrm{pA})$. Furthermore, the weighted mean conductance determined using nonstationary variance analysis is identical to that reported for glutamateevoked responses of cyclothiazide-treated GluR1 homomeric receptors, suggesting that desensitization does not involve a change in the relative proportions of subconductance levels (Irizarry et al., 1998). Thus, the most parsimonious explanation for our results is that the overall AMPA receptor open probability is controlled by $\mathrm{C} \alpha$-PKA phosphorylation of Ser845.

\section{GluR1 Ser845 control of $\boldsymbol{P}_{\mathrm{O}, \mathrm{PEAK}}$ and homosynaptic LTD}

Considerable data now suggest a role for dephosphorylation of GluR1 Ser845 in LTD, making it attractive to propose that this residue may be a substrate for the phosphatases implicated in postsynaptic forms of LTD [but see Bolshakov and Siegelbaum (1994) and Stevens and Wang (1994)]. Phosphorylation of Ser845 is reduced in LTD induced by application of NMDA to hippocampal slices (Lee et al., 1998). Complimentary experiments have shown that PKA activators can inhibit both LTD and associated GluR1 Ser845 phosphorylation and that cAMP analogs can reverse previously established LTD (Kameyama et al., 1998). Furthermore, selective inhibition of PKA also depresses synaptic AMPA receptor function and occludes LTD (Kameyama et al., 1998). Thus, our finding that conditions favoring dephosphorylation of GluR1 Ser845 reduce receptor $P_{\mathrm{O}, \mathrm{PEAK}}$ could provide a biophysical explanation for homosynaptic LTD at certain synapses. This idea is strengthened by recent experiments showing that hippocampal LTD is associated with a decrease in postsynaptic responses to glutamate (Kandler et al., 1998). Several reports suggest that protein phosphatases may control homo- synaptic hippocampal LTD through downregulation of AMPA receptor function. For example, Mulkey et al. (1994) have proposed that calcineurin relieves tonic inhibition of phosphatase $1 \mathrm{~A}$ through the inactivation of one of its phosphosubstrates, an endogenous phosphatase 1A inhibitor. Furthermore, Yan et al. (1999) have proposed that protein phosphatase-1 is directly associated with AMPA receptor complexes and attenuates receptor function. Although we cannot conclude or rule out dephosphorylation of GluR1 Ser845 by calcineurin in our experiments, our data are consistent with the hypothesis that dephosphorylation of GluR1 Ser845 may be involved in the expression of LTD.

\section{Biophysical mechanisms underlying the Ser845 control of GluR1 $P_{\text {O,PEAK }}$}

Perhaps the most puzzling aspect of these findings as well as a similar study of $\mathrm{PKA} /$ calcineurin regulation of homomeric GluR6 (Traynelis and Wahl, 1997) is the enhancement of $P_{\mathrm{O} \text {,PEAK }}$ that occurs in the absence of a marked change in response waveform. Several means by which phosphorylation could increase response amplitude without changing the response time course include phosphorylation-induced creation of rapidly equilibrating agonist-bound closed states or changes in channel opening rate, which would require offsetting changes in other rate constants to maintain a similar macroscopic response time course (Traynelis and Wahl, 1997). However, the lack of marked effects of PKA and calcineurin on both response time course and desensitization properties suggests that the changes in GluR1 function that occur after phosphorylation of Ser845 might be restricted to conformations that precede agonist binding. We have explored this idea using a simplified and arbitrary model of AMPA receptor function that embodies common features of several previously described kinetic schemes (Raman and Trussell, 1992; Jonas et al., 1993; Heckmann et al., 1996; Hausser 
Figure 9. Fluctuations between agonist unbound states can reduce $P_{\mathrm{O} \text {, PEAK. }} A$, The kinetic scheme was adapted from Heckmann et al. (1996), Jonas et al. (1993), and Hausser and Roth (1997), with changes made to the channel closing rate $\alpha$, channel opening rate $\beta$, rate constants for recovery from desensitization $k_{D-1}$ and $k_{D-2}$, and desensitization rate constant from the doubly liganded state $\mathrm{k}_{D+2}$. These changes resulted in a simulated response time course $(10-90 \%$ rise time to step rise in agonist $110 \mu \mathrm{sec}, \mathrm{tau}_{\text {DECAY }} 3.7 \mathrm{msec}$ for $10 \mathrm{~mm}$ glutamate), mean channel open time (625 $\mu \mathrm{sec})$, steady-state-peak current ratio (0.025), $\mathrm{EC}_{50}(0.4 \mathrm{~mm})$, and $\mathrm{tau}_{\text {RECOVERY }}$ from desensitization (180 $\mathrm{msec}$ ) that are similar to those measured for homomeric GluR1(flip) receptors (Mosbacher et al., 1994; Partin et al., 1996; Wahl et al., 1998; this study). The simulated agonist $\mathrm{EC}_{50}$ is also similar to that determined for CA1 pyramidal cells (0.42 mM) (Jonas and Sakmann, 1992), and $\mathrm{IC}_{50}$ for predesensitization $(10 \mu \mathrm{M})$ is similar to that determined for AMPA receptors in chick spinal neurons $(10$

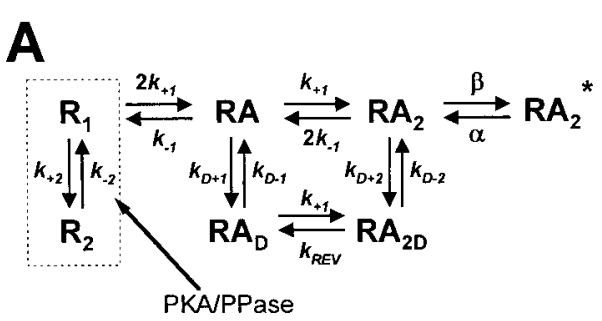

C

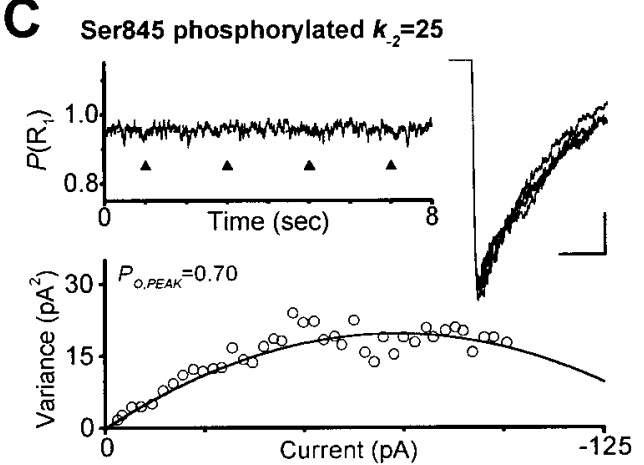

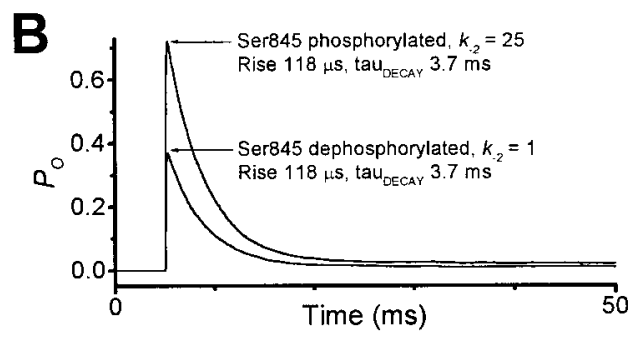

D Ser845 dephosphorylated $k_{-2}=1$

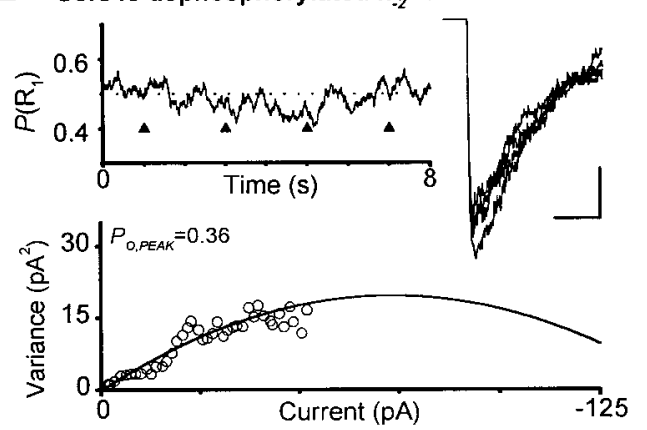

$\mu \mathrm{M})$ (Trussell and Fischbach, 1989) and CA1 hippocampal neurons (4-9 $\mu \mathrm{M})$ (Colquhoun et al., 1992). Responses were simulated by solving a Q-matrix (SCALCS provided by D. Colquhoun) as well as by using Monte Carlo methods. Rate constants (in $\mathrm{s}^{-1}$ ) were $k_{-1}=1500, k_{+2}=1, k_{-2}=1$ (Ser845-dephosphorylated receptor) or 25 (Ser845-phosphorylated receptor), $k_{\mathrm{D}+1}=100, k_{\mathrm{D}-1}=7, k_{\mathrm{D}+2}=4150, k_{\mathrm{D}-2}=7, \alpha=1600, \beta=2 \times 10^{4} \cdot k_{\mathrm{REV}}$ was adjusted to $72.2 \mathrm{sec}^{-1}$ to ensure microscopic reversibility, and the forward agonist binding constant $k_{+1}$ was $3.6^{2} \times 10^{6} \mathrm{~s}{ }^{-1} \mathrm{M}^{-1}$. $B$, Response time course is unchanged by partial occupancy of nonf unctional unbound state $\mathrm{R}_{2}$ despite large changes to $P_{\mathrm{O} \text {, PEAK}}$. The simulation was run with 96.2 or $50 \%$ of the channels starting in $\mathrm{R}_{1}$ for $k_{-2}=25$ or $1 \mathrm{~s}^{-1}$, respectively; the remainder of the channels started in state $\mathrm{R}_{2}$. $C$, Fluctuations during the response interval in the occupancy of the unbound state $\mathrm{R}_{1}$ are shown (top panel) when the rate constants between the two unbound states (R1 and R2) favor occupancy of state $\mathrm{R}_{1}$ at rest $\left(k_{+2}=1, k_{-2}=25 \mathrm{sec}^{-1}\right)$. Four responses at the times indicated by the arrows are superimposed to the right. Calibration: $2 \mathrm{msec}, 30 \mathrm{pA}$. The variance of responses of 200 channels $(12 \mathrm{pS}$ conductance, $-100 \mathrm{mV})$ was simulated by incorporating the fluctuations in the proportion of channels in state $\mathrm{R}_{1}$ at the start of agonist application. Fifty responses were simulated and analyzed as described in Materials and Methods for the model shown in $A$ with $k_{-2}=25 . D$, Fluctuations during the response interval in the occupancy of the unbound state $\mathrm{R}_{1}$ are shown when the rate constants between the two unbound states $\left(\mathrm{R}_{1}\right.$ and $\left.\mathrm{R}_{2}\right)$ are equal $\left(k_{+2}=k_{-2}=1 \mathrm{sec}^{-1}\right)$. Note the much larger fluctuations into and out of $\mathrm{R}_{1}$ for dephosphorylated receptor than for the phosphorylated receptor $(C)$. Four responses at the times indicated by the arrows are superimposed to the right. Calibration: $2 \mathrm{msec}, 20 \mathrm{pA}$. These traces illustrate the increased fluctuation of the peak current compared with $C$. The variance of responses of 200 channels (12 pS conductance, $-100 \mathrm{mV}$ ) were simulated by incorporating the fluctuations in the proportion of channels in state $\mathrm{R}_{1}$ at the start of an agonist application as indicated in $B$. Fifty responses were simulated and analyzed as described in Materials and Methods for the model shown in $A$ with $k_{-2}=1$. This analysis confirms that fluctuations in the occupancy of $\mathrm{R}_{1}$ before agonist application appear as a reduction in $P_{\mathrm{O}}$ PEAK, provided that fluctuations occur on a more rapid time scale $\left(\operatorname{tau}_{\text {EQUILIBRIum }}=0.5 \mathrm{sec}\right.$ for $\left.k_{-2}=1\right)$ than our stimulation protocol (inter-stimulus interval 2 sec) yet on a slower time scale than the duration of agonist application $(0.2 \mathrm{sec})$.

and Roth, 1997). The model described in Figure 9 is not presented as the definitive mechanism of AMPA receptor activation but rather is used here to evaluate the possibility that trial-to-trial changes in the number of active receptors might account for our results. In this model we hypothesize that phosphorylation of Ser845 alters the equilibrium between a resting unbound state $\left(\mathrm{R}_{1}\right)$ and an unbound nonf unctional state $\left(\mathrm{R}_{2}\right)$ during the interval between glutamate applications. Perturbations in this equilibrium that occur with a time constant less than the stimulus interval (2 $\mathrm{sec})$ but longer than the response decay time constant $(3 \mathrm{msec})$ effectively vary the number of receptors between trials (Fig. 9B) without changing the number of active receptors during a trial (Fig. 9C). Figure 9D confirms that fluctuations in the number of available receptors between agonist applications add variance throughout the current response and appear in our analysis as a decrease in peak open probability.

The central point of this model is that slow stochastic fluctuations in the occupancy of two unbound states $\left(\mathrm{R}_{1}\right.$ and $\left.\mathrm{R}_{2}\right)$ will appear as a decreased $P_{\text {O,PEAK }}$ without changing response time course, provided one of the states cannot proceed to the open state during agonist application. More work is required to compare this idea with other possible means of increasing $P_{\mathrm{O}, \mathrm{PEAK}}$, as well as to extend it to models of AMPA receptor activation that account for multiple conductance levels and multiple open states. Nevertheless, the model in Figure $9 A$ provides an interesting paradigm in which to consider AMPA receptor function. Moreover, if the increasingly complex network of intracellular proteins (GRIP, PICK1, NSF; $\alpha$ - and $\beta$-SNAPs) (Dingledine et al., 1999; Kim and Huganir, 1999) that bind to AMPA receptors within postsynaptic densities also control receptor function in a manner sensitive to the Ser845 phosphorylation, it would provide a physical correlate to the two functionally distinct unbound receptor conformations $\mathrm{R}_{1}$ and $\mathrm{R}_{2}$. Consistent in principle with this idea, C-terminal phosphorylation of Kir 2.3 by PKA (Cohen et al., 1996) and C-terminal phosphorylation of GluR2 by PKC (Matsuda et al., 1999) alter binding to PSD95 and GRIP, respectively. Interestingly, modifications of this model that reduce the equilibrium time constant between $R_{1}$ and $R_{2}$ below the stimulus interval produce an effective reduction in the number of receptors, an idea popularized by silent synapse models of synaptic plasticity (Gomperts et al., 1998; Kullmann and Asztely, 1998; Carroll et al., 1999). Thus, our findings, in addition to expanding our understanding of the molecular regulation of AMPA receptors, may 
have biophysical and structural implications for synaptic plasticity.

\section{REFERENCES}

Asztely F, Gustafsson B (1996) Ionotropic glutamate receptors. Their possible role in the expression of hippocampal synaptic plasticity. Mol Neurobiol 12:1-11.

Banke T, Traynelis SF (1998) Control of GluR1 activation by cAMPdependent protein kinase. Soc Neurosci Abtr 24:1272.

Barria A, Derkach V, Soderling T (1997) Identification of the $\mathrm{Ca}^{2+}$ calmodulin-dependent protein kinase II regulatory phosphorylation site in the $\alpha$-amino-3-hydroxy-5-methyl-4-isoxazole-propionate-type glutamate receptor. J Biol Chem 272:32727-32730.

Benke TA, Luthi A, Isaac JTR, Collingridge GL (1998) Modulation of AMPA receptor unitary conductance by synaptic activity. Nature 393:793-797.

Blackstone C, Murphy TH, Moss SJ, Baraban JM, Huganir RL (1994) Cyclic AMP and synaptic activity-dependent phosphorylation of AMPA-preferring glutamate receptors. J Neurosci 14:7585-7593.

Bolshakov VY, Siegelbaum SA (1994) Postsynaptic induction and presynaptic expression of hippocampal long-term depression. Science 264:1148-1152.

Boulter J, Hollmann M, O'Shea-Greenfield A, Hartley M, Deneris E, Maron C, Heinemann S (1990) Molecular cloning and functional expression of glutamate receptor subunit genes. Science 249:1033-1037.

Bowie D, Lange GD, Mayer ML (1998) Activity-dependent modulation of glutamate receptors by polyamines. J Neurosci 18:8175-8185.

Carroll RC, Lissin DV, von Zastrow M, Nicoll RA, Malenka RC (1999) Rapid redistribution of glutamate receptors contributes to long-term depression in hippocampal cultures. Nat Neurosci 2:454-460.

Chavez-Noriega LE, Stevens CF (1992) Modulation of synaptic efficacy in field CA1 of the rat hippocampus by forskolin. Brain Res 574:85-92.

Chen C, Okayama H (1987) High efficiency transformation of mammalian cells by plasmid DNA. Mol Cell Biol 7:2745-2752.

Coghlan VM, Perrino BA, Howard M, Langeberg LK, Hicks JB, Gallatin WM, Scott JD (1995) Association of protein kinase A and protein phosphatase $2 \mathrm{~B}$ with a common anchoring protein. Science 267:108-111.

Cohen NA, Brenman JE, Snyder SH, Bredt DS (1996) Binding of the inward rectifier $\mathrm{K}^{+}$channel Kir 2.3 to PSD-95 is regulated by protein kinase A phosphorylation. Neuron 17:759-767.

Colquhoun D, Hawkes AG (1977) Relaxation and fluctuations of membrane currents that flow through drug-operated channels. Proc R Soc Lond B Biol Sci 199:231-262.

Colquhoun D, Sigworth FJ (1995) Fitting and statistical analysis of single channel records. In Single-channel recording (Sakman B, Neher E, eds), pp 483-588. New York: Plenum.

Colquhoun D, Jonas P, Sakmann B (1992) Action of brief pulses of glutamate on AMPA/kainate receptors in patches from different neurones of rat hippocampal slices. J Physiol (Lond) 458:261-287.

Cull-Candy SG, Usowicz MM (1987) Multiple conductance channels activated by excitatory amino acids in cerebellar neurons. Nature 325:525-528

Cull-Candy SG, Howe JR, Ogden DC (1988) Noise and single channels activated by excitatory amino acids in large cerebellar neurons of the rat. J Physiol (Lond) 400:189-222.

Derkach V, Barria A, Soderling TR (1999) $\mathrm{Ca}^{2+} /$ calmodulin-kinase II enhances channel conductance of $\alpha$-amino-3-hydroxy-5-methyl-4isoxazolepropionate type glutamate receptors. Proc Natl Acad Sci USA 96:3269-3274.

Dingledine R, Borges K, Bowie D, Traynelis SF (1999) The glutamate receptor ion channels. Pharmacol Rev 51:7-61.

Fraser IDC, Scott JD (1999) Modulation of ion channels: a current view of AKAPS. Neuron 23:423-426.

Gomperts SN, Rao A, Craig AM, Malenka RC, Nicoll RA (1998) Postsynaptically silent synapses in single neuron cultures. Neuron 21:1443-1451.

Greengard P, Jen J, Nairn AC, Stevens CF (1991) Enhancement of the glutamate response by cAMP-dependent protein kinase in hippocampal neurons. Science 253:1135-1138.

Hausser M, Roth A (1997) Dendritic and somatic glutamate receptor channels in rat cerebellar Purkinje cells. J Physiol (Lond) 501:77-95.

Heckmann M, Bufler J, Franke C, Dudel J (1996) Kinetics of homomeric GluR6 glutamate receptor channels. Biophys J 71:1743-1750.
Heinemann SH, Conti F (1992) Nonstationary noise analysis and application to patch clamp recordings. Methods Enzymol 207:131-148.

Hestrin S (1992) Activation and desensitization of glutamate-activated channels mediating fast excitatory synaptic currents in the visual cortex. Neuron 9:991-999.

Hollmann M, Heinemann SF (1994) Cloned glutamate receptors. Annu Rev Neurosci 17:31-108.

Huggenvik JI, Collard MW, Stofko RE, Seasholtz AF, Uhler MD (1991) Regulation of the human enkephalin promoter by two isoforms of the catalytic subunit of cyclic adenosine $3^{\prime} 5^{\prime}$-monophosphate-dependent protein kinase. Mol Endocrinol 5:921-930.

Irizarry SN, Pemberton KE, Howe JR (1998) Agonist-specific differences in the unitary properties of homomeric GluR1 receptors. Soc Neurosci Abstr 24:847.

Jahr CE, Stevens CF (1987) Glutamate activates multiple single channel conductances in hippocampal neurons. Nature 325:522-525.

Jonas P, Sakmann B (1992) Glutamate receptor channels in isolated patches from CA1 and CA3 pyramidal cells of rat hippocampal slices. J Physiol (Lond) 455:143-171.

Jonas P, Major G, Sakmann B (1993) Quantal components of unitary EPSCs at the mossy-fibre synapse on CA3 pyramidal cells of rat hippocampus. J Physiol (Lond) 472:615-663.

Kameyama K, Lee H-K, Bear MF, Huganir RL (1998) Involvement of a postsynaptic protein kinase A substrate in the expression of homosynaptic long-term depression. Neuron 21:1163-1175.

Kandler K, Katz LC, Kauer JA (1998) Focal photolysis of caged glutamate produces long-term depression of hippocampal glutamate receptors. Nat Neurosci 1:119-123.

Keller BU, Hollmann M, Heinemann S, Konnerth A (1992) Calcium influx through subunits GluR1/GluR3 of kainate/AMPA receptor channels is regulated by cAMP dependent protein kinase. EMBO J 11:891-896.

Kim YH, Huganir RL (1999) Organization and regulation of proteins at synapses. Curr Opin Cell Biol 2:248-254.

Knapp AG, Schmidt KF, Dowling JE (1990) Dopamine modulates the kinetics of ion channels gated by excitatory amino acids in retinal horizontal cells. Proc Natl Acad Sci USA 87:767-771.

Kullmann DM, Asztely F (1998) Extrasynaptic glutamate spillover in the hippocampus: evidence and implications. Trends Neurosci 21:8-14.

Kullmann DM, Siegelbaum SA (1995) The site of expression of NMDA receptor-dependent LTP: new fuel for an old fire. Neuron 15:997-1002.

Lee H-K, Kameyama K, Huganir RL, Bear MF (1998) NMDA induces long-term synaptic depression and dephosphorylation of the GluR1 subunit of AMPA receptors in hippocampus. Neuron 21:1151-1162.

Leranth C, Szeidemann Z, Hsu M, Buzsaki G (1996) AMPA receptors in the rat and primate hippocampus: a possible absence of GluR2/3 subunits in most interneurons. Neuroscience 70:631-652.

Levenes C, Daniel H, Crepel F (1998) Long-term depression of synaptic transmission in the cerebellum: cellular and molecular mechanisms revisited. Prog Neurobiol 55:79-91.

Linden DJ (1994) Long-term synaptic depression in the mammalian brain. Neuron 12:457-472.

Malenka RC, Nicoll RA (1999) Long-term potentiation-a decade of progress? Science 285:1870-1874.

Mammen AL, Kameyama K, Roche KW, Huganir RL (1997) Phosphorylation of the $\alpha$-amino-3-hydroxy-5-methylisoxazole-4-propionic acid receptor GluR1 subunit by calcium/calmodulin-dependent kinase II. J Biol Chem 272:32528-32533.

Maren S, Baudry M (1995) Properties and mechanisms of long-term synaptic plasticity in the mammalian brain: relationships to learning and memory. Neurobiol Learn Mem 63:1-18.

Marshall J, Molloy R, Moss GW, Howe JR, Hughes TE (1995) The jellyfish green fluorescent protein: a new tool for studying ion channel expression and function. Neuron 14:211-215.

Matsuda S, Mikawa S, Hirai H (1999) Phosphorylation of serine-880 in GluR2 by protein kinase $\mathrm{C}$ prevents its $\mathrm{C}$ terminus from binding with glutamate receptor-interacting protein. J Neurochem 73:1765-1768.

Monyer H, Seeburg PH, Wisden W (1991) Glutamate-operated channels: developmentally early and mature forms arise by alternative splicing. Neuron 6:799-810.

Mosbacher J, Schoepfer R, Monyer H, Burnashev N, Seeburg PH, Ruppersberg JP (1994) A molecular determinant for submillisecond desensitization in glutamate receptors. Science 266:1059-1062.

Mulkey RM, Endo S, Shenolikar S, Malenka RC (1994) Involvement of 
a calcineurin/inhibitor-1 phosphatase cascade in hippocampal longterm depression. Nature 369:486-488.

Neher E, Stevens CF (1977) Conductance fluctuations and ionic pores in membranes. Annu Rev Biophys Bioeng 6:345-381.

Partin KM, Fleck MW, Mayer ML (1996) AMPA receptor flip/flop mutants affecting deactivation, desensitization, and modulation by cyclothiazide, antiracetam, and thiocyanate. J Neurosci 16:6634-6647.

Pearson RB, Kemp BE (1991) Protein kinase phosphorylation site sequences and consensus specificity motifs: tabulations. Methods Enzymol 200A:62-81.

Raman IM, Trussell LO (1992) The kinetics of the response to glutamate and kainate in neurons of the avian cochlear nucleus. Neuron 9:173-186.

Raman IM, Trussell LO (1995) Concentration-jump analysis of voltage dependent conductances activated by glutamate and kainate in neurons of the avian cochlear nucleus. Biophys J 69:1868-1879.

Rison RA, Stanton PK (1995) Long-term potentiation and $N$-methyl-Daspartate receptors: foundations of memory and neurologic disease? Neurosci Biobehav Rev 19:533-552.

Roberson ED, Sweatt JD (1996) Transient activation of cyclic AMPdependent protein kinase during hippocampal long-term potentiation. J Biol Chem 271:30436-30441.

Roche KW, O’Brien RJ, Mammen AL, Bernhardt J, Huganir RL (1996) Characterization of multiple phosphorylation sites on the AMPA receptor GluR1 subunit. Neuron 16:1179-1188.

Rosenmund C, Carr DW, Bergeson SE, Nilaver G, Scott JD, Westbrook GL (1994) Anchoring of protein kinase A is required for modulation of AMPA/kainate receptors on hippocampal neurons. Nature 368:853-856.

Rosenmund C, Stern-Bach Y, Stevens CF (1998) The tetrameric structure of a glutamate receptor channel. Science 280:1596-1599.

Sigworth FJ (1980) The variance of sodium current fluctuations at the node of Ranvier. J Physiol (Lond) 307:97-129.

Silberberg SD, Magleby KL (1993) Preventing errors when estimating single channel properties from the analysis of current fluctuations. Biophys J 65:1570-1584.

Sommer B, Keinanen K, Verdoorn TA, Wisden W, Burnashev N, Herb A, Kohler M, Takagi T, Sakmann B, Seeburg PH (1990) Flip and flop: a cell-specific functional switch ion glutamate-operated channels of the CNS. Science 249:1580-1585.

Spruston N, Jonas P, Sakmann B (1995) Dendritic glutamate receptor channels in rat hippocampal CA3 and CA1 pyramidal neurons. J Physiol (Lond) 482:325-352.

Stern-Bach Y, Bettler B, Hartley M, Sheppard PO, O'Hara PJ, Heinemann SF (1994) Agonist selectivity of glutamate receptors is specified by two domains structurally related to bacterial amino acid-binding proteins. Neuron 13:1345-1357.

Stevens CF, Wang Y (1994) Changes in reliability of synaptic function as a mechanism for plasticity. Nature 371:704-707.
Swanson GT, Feldmeyer D, Kaneda M, Cull-Candy SG (1996) Effect of RNA editing and subunit co-assembly on single-channel properties of recombinant kainate receptors. J Physiol (Lond) 492:129-142.

Swanson GT, Kamboj SK, Cull-Candy SG (1997) Single-channel properties of recombinant AMPA receptors depend on RNA editing, splice variation, and subunit composition. J Neurosci 17:58-69.

Traynelis SF, Jaramillo F (1998) Making the most out of noise in the central nervous system. Trends Neurosci 21:137-145.

Traynelis SF, Wahl P (1997) Control of GluR6 receptor open probability by protein kinase A and calcineurin. J Physiol (Lond) 503:513-531.

Trussell LO, Fischbach GD (1989) Glutamate receptor desensitization and its role in synaptic transmission. Neuron 3:209-218.

Tzounopoulos T, Janz R, Sudhof TC, Nicoll RA, Malenka RC (1998) A role for cAMP in long-term depression at hippocampal mossy fiber synapses. Neuron 21:837-845.

Wahl P, Anker C, Traynelis SF, Egebjerg J, Rasmussen JS, KrogsgaardLarsen P, Madsen U (1998) Antagonist properties of a phosphono isoxazole amino acid at GluR1-4 $(R, S)$-2-amino-3-(3-hydroxy-5methyl-4-isoxazolyl)propionic acid receptor subtypes. Mol Pharmacol 53:590-596.

Wang J-H, Kelly PT (1997) Postsynaptic calcineurin activity downregulates synaptic transmission by weakening intracellular $\mathrm{Ca}^{2+}$ signaling mechanisms in hippocampal CA1 neurons. J Neurosci 17:4600-4611.

Wang J-H, Stelzer A (1994) Inhibition of phosphatase 2B prevents expression of hippocampal long-term potentiation. NeuroReport $5: 2377-2380$.

Wang LY, Salter MW, MacDonald JF (1991) Regulation of kainate receptors by cAMP-dependent protein kinase and phosphatases. Science 253:1132-1135.

Wang X, Murphy TJ (1998) Inhibition of cyclic AMP-dependent kinase by expression of a protein kinase inhibitor/enhanced green fluorescent fusion protein attenuates angiotensin II-induced type $1 \mathrm{AT}_{1}$ receptor mRNA down-regulation in vascular smooth muscle cells. Mol Pharmacol 54:514-524.

Washburn MS, Numberger M, Zhang S, Dingledine R (1997) Differential dependence of GluR2 expression of three characteristic features of AMPA receptors. J Neurosci 17:9393-9406.

Wyllie DJA, Traynelis SF, Cull-Candy SG (1993) Evidence for more than one type of non-NMDA receptor in outside-out patches from rat cerebellar granule cells. J Physiol (Lond) 463:193-226.

Yan Z, Hsieh-Wilson L, Feng J, Tomizawa K, Allen PB, Fienberg AA, Nairn AC, Greengard P (1999) Protein phosphatase 1 modulation of neostriatal AMPA channels: regulation by DARP-32 and spinophilin. Nat Neurosci 2:13-17.

Yan-You H, Kandel ER (1998) Postsynaptic induction and PKAdependent expression of LTP in the lateral amygdala. Neuron 21:169-178.

Zar JH (1999) Biostatistical analysis. Upper Saddle River, NJ: Prentice Hall. 